\title{
Attempt on Magnification of the Mechanism of Enzyme Catalyzed Reaction through Bio-geometric Model for the Five Points Circle in the Triangular Form of Lineweaver-Burk Plot
}

\author{
Vitthalrao Bhimasha Khyade ${ }^{\text {a, b, c,* }}$, Avram Hershko ${ }^{\text {d }}$ \\ ${ }^{a}$ Sericulture Unit, Malegaon Sheti Farm, Agricultural Development Trust Baramati, Shardanagar, Maharashtra, India \\ ${ }^{b}$ Department of Zoology, Shardabai Pawar Mahila Mahavidyalaya, Shardanagar Tal. Baramati Dist. Pune - 413115, India \\ ${ }^{c}$ Dr. APIS, Shrikrupa Residence, Teachers Society, Malegaon Colony (Baramati) Dist. Pune - 413115, India \\ ${ }^{d}$ Unit of Biochemistry, The B. Rappaport Faculty of Medicine, and the Rappaport Institute for Research in the Medical Sciences, \\ Technion-Israel Institute of Technology, Haifa 31096, Israel
}

\section{Authors' Contributions}

This work was carried out in collaboration between all authors. V. B. Khyade carried out the research work, supervised by A. Hershko. Both authors (V. B. Khyade and A. Hershko) performed statistical analysis. Revision of the manuscript as well as corrections were made and approved by both authors.

\section{ARTICLE INFO}

Article history:

Received 26 August 2020

Received in revised form 23 September 2020

Accepted 22 October 2020

Available online

23 October 2020

Keywords:

Bio-geometric model

Double reciprocal plot

Enzyme

Five point circle

Substrate

Triangular form

\section{ABSTRACT}

The bio-geometrical model is dealing with correlation between the "five events for enzyme catalyzed reaction" and "triple point event serving groups on the circle" in triangle obtained for the graphical presentation of the double reciprocal for magnification of the mechanism of enzyme catalyzed reaction. This model is based on the nine point circle in triangle of the double reciprocal plot. The five significant points (B, D, E, F and G) resulted for the circle with $\mathrm{x}-$ and $\mathrm{y}$ - coordinates. The present attempt is considering interactions among enzymes and substrates for the successful release of product through each and every point on the circle in triangle. The controlling role of the point, "O", center of circle in each and every event of the biochemical reaction is obligatory. The model is allotting specific role for the significant events in the biochemical reaction catalyzed by the enzymes. The enzymatic catalysis is supposed to be completed through five events, which may be named as, "Bio-geometrical events of enzyme catalyzed reaction". These five events for enzyme catalyzed reaction include: (1) Initial event of enzymatic interaction with the substrates; (2) Event of the first transition state for the formation of "enzyme-substrate" complex; (3) Event of the second transition state for the formation of "enzyme-product" complex; (4) Event of release of the product and relieve enzyme and (5) The event of directing the enzyme to continue the reaction. The model utilizes the "triple point serving group on the circle" for the success of each and every event in the biochemical reaction. Thus, there is involvement of the three points including the point " $\mathrm{O}$ " for each event in the enzyme catalyzed reaction. The group of points serving for carrying out the event may be classified into five conic sections like: B-O-E; E-O-G; G-O-D; D-O-F and F-O-B. The bio-geometrical model is correlation between the "five events for enzyme catalyzed reaction" and "triple point event serving groups on the circle" in a triangle of the double reciprocal plot.

https://doi.org/10.37121/ijesr.v1.120

\footnotetext{
* Corresponding author

E-mail address: vbkhyade.2016@gmail.com
}

2756-6773 / (C) 2020 the authors. Published by Sciengtex. This is an open access article under CC BY-NC-ND license (http://creativecommons.org/licenses/by-nc-nd/4.0/) 


\section{Introduction}

Enzymes are the protein biomolecules dealing with manipulation of other biomolecules in the form of the substrates or target biomolecules. The possible aim of binding the enzyme-active-site with the molecule of respective substrate (or target) is efficient available favorable cytoplasmic conditions. The interplay of the enzymes is serving a lot for the progression biochemical reactions. Enzyme kinetics deals with the study of the biochemical reactions controlled by the enzymes. It is a branch of biochemistry for the measurement of rates of bio-chemical reactions. The changes in rate of reaction according to the change in the conditions in the reaction system are also concerned with kinetics of the enzymes. The study attempts on enzymatic is helping to reveal catalysis mechanism through the enzymes and key role of the enzymes [1]. Significant feature of enzyme biochemistry lies in the "Michaelis-Menten equation". Credit goes to the efforts of Leonor Michaelis and Maud Leonora Menten. Leonor Michaelis (Birth: 16 January, 1875 Death: 8 October, 1949) was a German biochemist (and a physician too) [2]. Maud Leonora Menten (Birth: 20 March, 1879 - Death: 17 July, 1960) was of Canadian biochemist [2]. She was the medical researcher. Both of them established significant research contributions to the biochemistry of the enzymes and histochemistry. From 1913, their research work is recognized as the equation of "Michaelis-Menten". The biochemical reaction is:

$(\mathrm{E})+(\mathrm{S}) \stackrel{*}{\rightarrow}(\mathrm{ES}) \stackrel{* *}{\rightarrow}(\mathrm{E})+(\mathrm{P})$.

Given that: (E), (S), (ES) and (P) in equation (1) denotes the Enzyme; Substrate; Enzyme-SubstrateComplex and the Product respectively.

Leonor Michaelis and Maud Leonora Menten supposed that, in very first step, the enzyme combines with the substrate. This combination is for the purpose to form "E.S" complex. The "ES" complex, in its turn deserves ability of conversion into the product ("P"). Significant feature of this reaction is preservation of the enzyme as it is. The volume or amount of the formation of "ES" complex per unit time is recognized as " $\mathrm{k}_{1}$ " $(*)$ (or the first forward reaction rate). Volume or amount of the "P" (product) per unit time is recognized as " $\mathrm{k}_{2}$ " $(* *)$ (or the rate of the second forward reaction). There is possibility of dissolution of the "ES" complex back again into the enzyme-entity and substrate-entity. Generally, the reaction moves forward to form product ("P") [3]. The Fig. 1 deals with the effects of the substration - concentrations [S] on the velocities of reaction catalyzed by the enzymes.

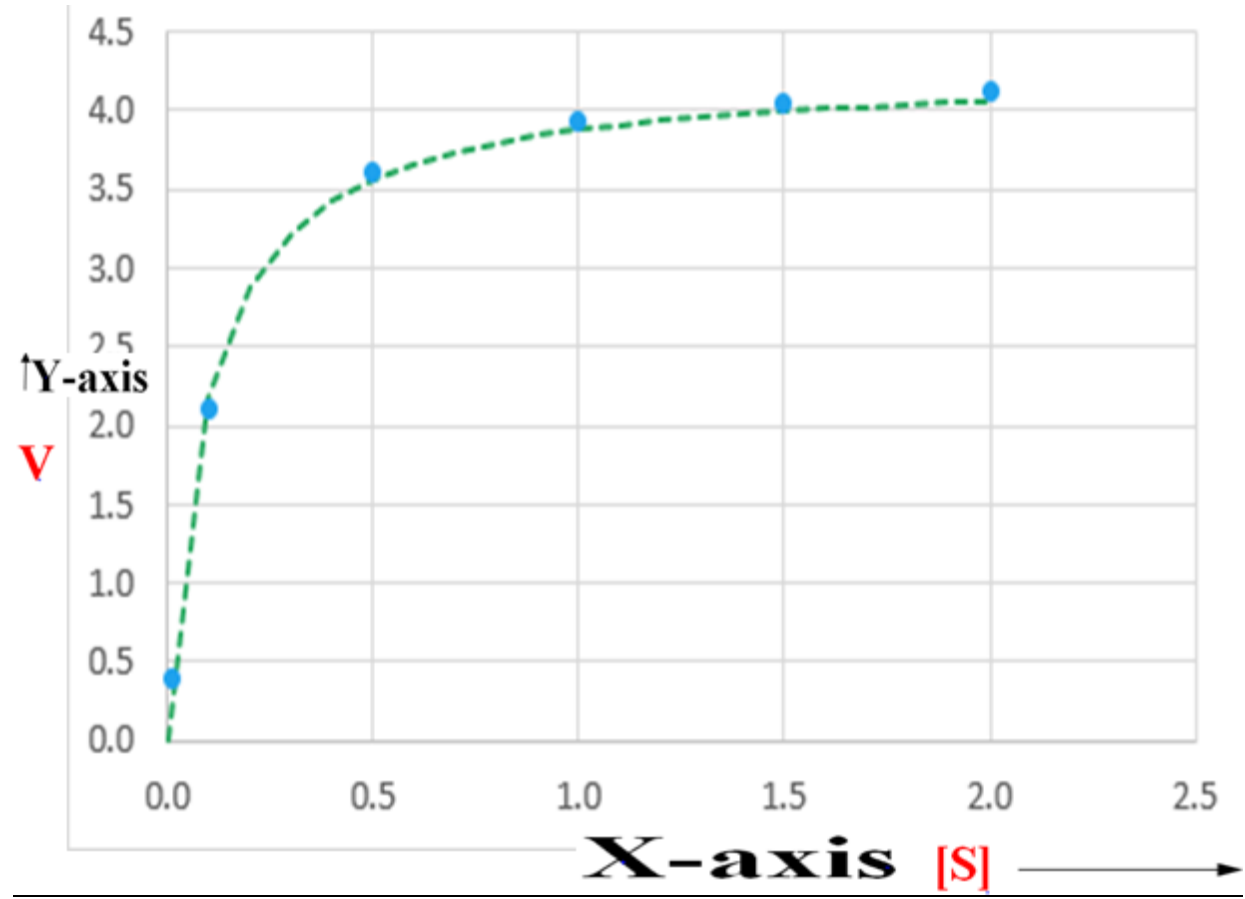

Fig. 1 Effects of the substration-concentrations $[\mathrm{S}]$ on the velocities of reaction catalyzed by the enzymes

At the very first or initial stage (initial reaction time), little product formation occurs. Therefore, the $\mathrm{k}_{-2}$ may be neglected. The generalized form of biochemical reaction expected by Michaelis-Menten equation may be written as:

$(\mathrm{E})+(\mathrm{S}) \stackrel{\mathrm{k}_{-1}}{\leftrightarrow}(\mathrm{E} . \mathrm{S}) \stackrel{\mathrm{k}_{-2}}{\rightarrow}(\mathrm{E})+(\mathrm{P})$.

Assumptions for the state of steady reaction, the equation may be transformed as: 
(E.S) $\stackrel{\mathrm{k}_{-1}}{\rightarrow}(\mathrm{E})+(\mathrm{S})$.

The formation rate for $(E \cdot S)=k_{1} .(E) .(S)$. The rates of breakdown of $(E \cdot S)=\left(k_{-1}+k_{2}\right)(E \cdot S)$ and sets equals to each other (bracket represents concentration). It means,

$\mathrm{k}_{1}(\mathrm{E}) \cdot(\mathrm{S})=\left(\mathrm{k}_{-1}+\mathrm{k}_{2}\right)(\mathrm{E} \cdot \mathrm{S})$.

Equation (4) can be written (rearranging terms) as:

$[(\mathrm{E}) \times(\mathrm{S})] /(\mathrm{E} . \mathrm{S})=\left(\mathrm{k}_{-1}+\mathrm{k}_{2}\right) /\left(\mathrm{k}_{2}\right)$.

The fraction $[(\mathrm{E}) .(\mathrm{S})] \div[(\mathrm{E} . \mathrm{S})]$ has been coined as: $\mathrm{K}_{\mathrm{m}}$, or the Michaelis-Menten constant. As per the expectation of the enzyme kinetics equation (Enzyme kinetics of Michaelis-Menten), at the low substrate concentration [S], the concentrations is almost negligible in the denominator position as $\mathrm{K}_{\mathrm{m}}>>[\mathrm{S}]$. Therefore, the Michaelis-Menten equation is essentially become:

$\mathrm{V}_{\mathrm{o}}=\mathrm{V}_{\max }[\mathrm{S}] \div \mathrm{K}_{\mathrm{m}}$.

Equation (6) is appearing as a first order-reaction. As the substrate concentration exceeding, $[\mathrm{S}] \gg>\mathrm{K}_{\mathrm{m}}$. Therefore, the term $[\mathrm{S}] \div\left([\mathrm{S}]+\mathrm{K}_{\mathrm{m}}\right)$ becomes essentially one and the initial velocity approached $V_{\max }$. And now the equation resembles zero order reaction [4]. The Michaelis-Menten equation is:

$\mathrm{V}_{0}=\left[\mathrm{V}_{\max } \mathrm{S} \div\left(\mathrm{K}_{\mathrm{m}}+\mathrm{S}\right)\right]$.

$\mathrm{V}_{0}$ is the initial velocity of the reaction. In equation (7), the term " $V_{\max }$ " is used for the maximum rate of the reaction; the term " $\mathrm{S}$ " is used for the concentration of the substrate and the term " $K_{\mathrm{m}}$ " is used for the Michaelis-Menten constant for biochemical reaction. Michaelis-Menten constant $\left(K_{\mathrm{m}}\right)$ denotes the concentration of the substrate when the reaction velocity $(\mathrm{V})$ is equal to one half of the maximum. Michaelis-Menten constant $\left(K_{\mathrm{m}}\right)$ can also be thought of as a measure of how well a substrate complexes with a given enzyme, otherwise known as its binding affinity. Biochemical reaction with lower value for $K_{\mathrm{m}}$ is the feature of higher affinity of enzyme for the substrate. Biochemical reaction with lower value for $K_{\mathrm{m}}$ is going to attain the maximum velocity $\left(V_{\max }\right)$ within short period. Biochemical reaction with higher value for $K_{\mathrm{m}}$ is the feature of lower affinity of enzyme for the substrate. Biochemical reaction with higher value for $K_{\mathrm{m}}$ is going to attain the maximum velocity $\left(V_{\max }\right)$ after longer period of duration [5]. Keeping the concentration of enzyme constant, if the concentration of substrates $[S]$ in a reaction system increased, the active sites on the proteins (within the enzyme) are going to be locked with substrate. Now the reaction is proceeding with change in earlier rate. The steady state of the reaction is supposed to be achieved if and only if "all the active sites within the structure" get locked. That is to say, the higher substrate concentration is to orchestrate the progression of biochemical reaction through the saturation (of enzyme-active-sites with respective substrate).

The rate (or velocity) of biochemical reaction is dependent on the conditions of reaction system, which include: Substrate volume or amount (in real sense, the concentration); hydrogen ion concentration (pH); temp.; enzyme volume or amount (in real sense, the concentration of the enzyme); activator and inhibitor. The linear response of reaction rate (velocity of bio-catalyzed reaction) for the changes (increase in) in the concentration of the substrate is theoretical expectation. Practically, there is no linear response of reaction rate (velocity of bio-catalyzed reaction) for the changes (increase in) in the concentration of the substrate. This difference (in the theoretical and practical expectation for the enzyme reaction rate) may be due to difference in the extent of saturation of enzymes with substrates. The reaction rate (initial velocity) is exhibiting increasing tendency according to the increase in the concentration of substrate. The tendency of increase reaction rate is observed only up to certain level of the concentration of substrate [S]. Up to this substrate concentration [S], there is saturation of the enzyme with the substrate. This condition is responsible for reaction rate to attain its maximum $\left(V_{\max }\right)$. The maximum rate of enzyme reaction (maximum velocity or $\left.V_{\max }\right)$ is equal to the product of the catalyst rate constant $\left(k_{\text {cat }}\right)$ and the concentration of the enzyme. Accordingly, the enzyme-kinetic reaction can be written as:

Enzyme reaction rate $(\mathrm{V})=\left[\mathrm{K}_{\mathrm{cat}}(\right.$ Enzyme $\left.) .(\mathrm{S})\right] \div\left[\left(\mathrm{K}_{\mathrm{m}}+\mathrm{S}\right)\right]$.

The $K_{\text {cat }}$ is equal to K.2. The $K_{\text {cat }}$ (or K.2) is measuring the number of molecules of substrate turnedover through the action of the enzyme per unit time (second). One per second is the unit for $K_{\text {cat. }}$ The time required by an enzyme to turn-over a substrate molecule is the reciprocal of $K_{\text {cat. }}$. The higher the $K_{\text {cat }}$ appears to be the distinguishing features of the more substrates get turned-over in one unit time (second). The Michaelis.Menten equation is defining the "Michaelis-Menten" constant $\left(K_{\mathrm{m}}\right)$ as, "the concentration of substrates for the enzyme reaction to reach the rate of reaction half of its maximum $\left(V_{\max }\right)$. The enzyme 
with smaller Km exhibits higher affinity for the substrate. For such enzymes, the reaction can reach half of $V_{\max }$ in a small number of substrate concentrations. This small $K_{\mathrm{m}}$ will approach $V_{\max }$ more quickly than high $K_{\mathrm{m}}$ value [5].

The second figure (Fig. 2) is dealing with the graph representing the response of reciprocal of enzyme reaction rate $(1 \div \mathrm{V})$ to the reciprocal of concentration of substrate $(1 \div \mathrm{S})$. This graph is recognized as: the double reciprocal (or the Lineweaver-Burk) plot. The response of reciprocal of enzyme reaction rate $(1 \div \mathrm{V})$ to the reciprocal of concentration of substrate $(1 \div \mathrm{S})$ is in the form of straight line. Geometrical slope for the line is $\left(\mathrm{K}_{\mathrm{m}} \div \mathrm{V}_{\text {max }}\right.$.). Geometrical intercept of the line on the $\mathrm{Y}$ - axis is $\left(1 \div \mathrm{V}_{\max }\right)$. Geometrical intercept of the line on the $\mathrm{X}-$ axis is $\left[-\left(1 \div \mathrm{K}_{\mathrm{m}}\right)\right]$. This double reciprocal plot (or Lineweaver-Burk plot) is serving a lot, particularly for the analysis of rate of enzyme involved reactions.

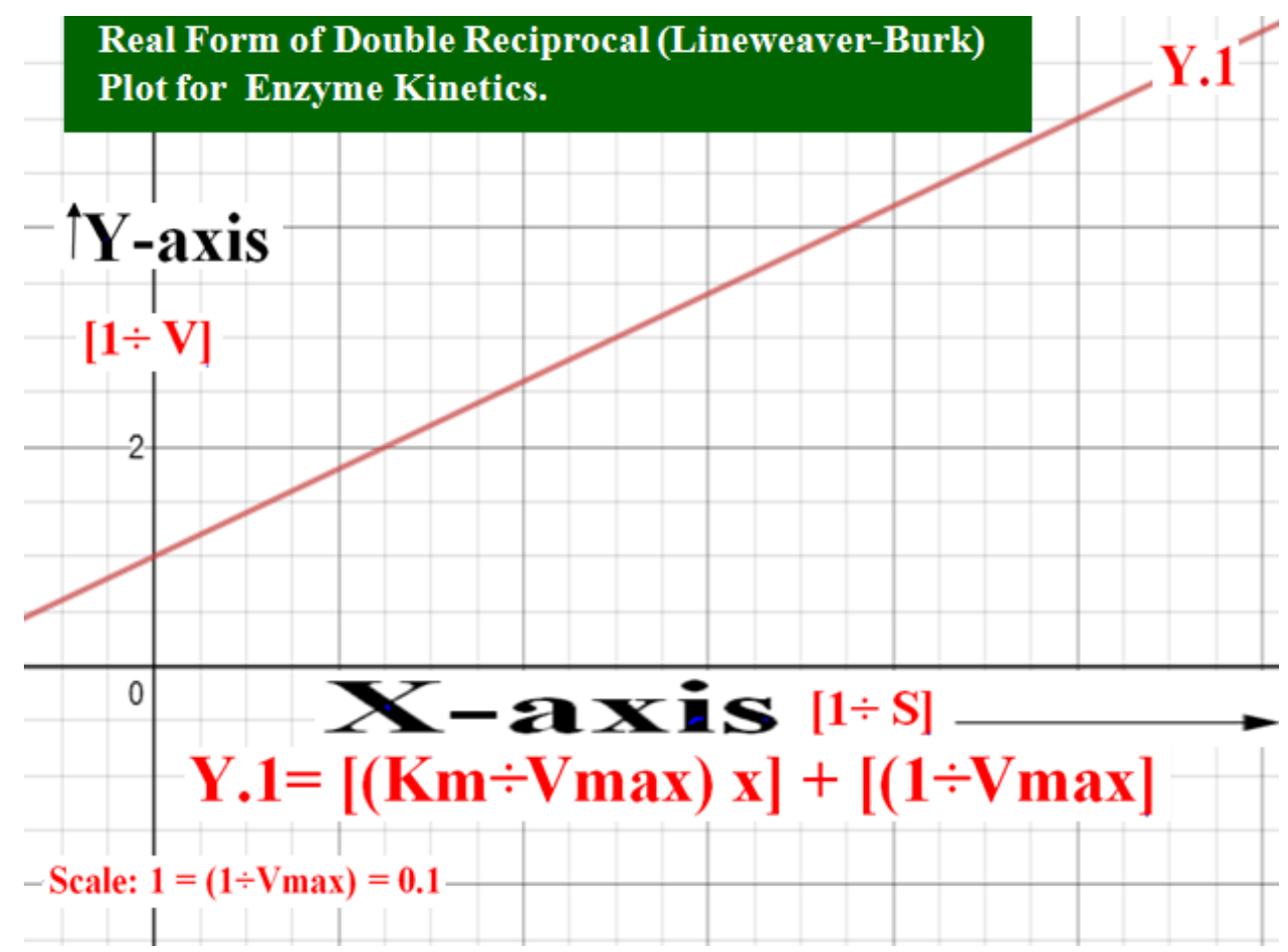

Fig. 2 The real form of double reciprocal (Lineweaver-Burk) plot

There are inhibitors (competitive, non-competitive, or a mixture of the two) for the enzyme action. The competitive, uncompetitive, non-competitive and mixed types of inhibitors constitute the major four categories. Their action can be presented with the help of principles of the double reciprocal-plot. The competitive-inhibitors are appearing exactly like substrates. The competitive-inhibitors deserve capacity to bind the active site of the enzyme. The competitive-inhibitors are known to exert decreased tendency in the reaction rate. The competitive-inhibitors are known for increase $K_{\mathrm{m}}$ value of given enzyme. The competitive-inhibitors decrease affinity of the enzymes for substrate. There is less chance for the substrates to reach active site of the enzymes. There is no effect of competitive inhibitors on the maximum velocity of the reaction. The maximum velocity $\left(V_{\max }\right)$ of the reaction remains the same. There is change in the slope of line plotted for double reciprocal (Lineweaver-Burk) plot, for enzyme with the "competitive-inhibitor" as compared to the slope of the line plotted for double reciprocal (Lineweaver-Burk) plot, for enzyme without the "competitive-inhibitor". The distinguishing feature of uncompetitive inhibitors is close binding to the active site of enzyme and not occupying the active site of enzyme [6], [7]. This feature get exert to the lower $K_{\mathrm{m}}$ (increase affinity) and lower $V_{\max }$ for the reaction with "uncompetitive-inhibitors". The "noncompetitive-inhibitors" are without capacity of binding to the active site of the enzyme. But, the "noncompetitive-inhibitors" may bind somewhere on the enzyme, leads into the change in enzyme structure and rate of reaction. The "non-competitive-inhibitors" are with the same $K_{\mathrm{m}}$ value but lower $V_{\max }$ (in comparison with enzyme reaction without inhibitors). $K_{\mathrm{m}}$ value for the "non-competitive-inhibitors" is numerically equal to the substrate concentration at which the half of the enzyme molecules are associated with substrate. It clearly indicates that, the $K_{\mathrm{m}}$ value is an "Index" of the affinity of enzyme for its specific (or particular) substrate [8]-[11].

Most of the research journals in biochemistry contain the text on the double-reciprocal, or LineweaverBurke plot. It is widely used in research to extract kinetic parameters, such as the $V_{\max }, K_{\mathrm{m}}$, and $K_{\mathrm{i}}$ values. The double-reciprocal, or Lineweaver-Burke plot has long been recognized for the process of taking 
reciprocals. The smallest reading on substrate concentration $[\mathrm{S}]$ and velocity of reaction (v) have the most influence. Various graphical and later analytical (non-linear regression) solutions have been proposed over the years, but the double reciprocal plot remains the standard. Its standardization lies in the pattern recognition of the three principal forms of reversible enzyme inhibition reactions for: competitive enzymes, uncompetitive enzymes, and non-competitive enzymes. Still, a separate problem coexists with double reciprocal plots. It is seldom mentioned that, double reciprocal is strongly anti-intuitive [12].

In enzyme kinetics, a linear-regression is used for the determination the slope $\left(K_{\mathrm{m}} \div V_{\max }\right)$ and intercepts (x- and y-) and for the approximation of the $K_{\mathrm{m}}$ and for the approximation of the $V_{\max }$. The double reciprocal plot (or Lineweaver-Burk-plot) is useful in the analysis of the behavior of enzymes in a given system of reaction. The double reciprocal plot (or Lineweaver-Burk-plot) gives a more accurate estimate of $V_{\max }$ and more accurate information about inhibition. It increases the precision by linearizing the data on substrate concentration and reaction rate of enzyme involved reaction system. The values for $K_{\mathrm{m}}$ and $V_{\max }$ can thus be determined precisely and the error can be estimated quantitatively.

There are some limitations with double reciprocal plot (or Lineweaver-Burk-plot). The data points in one region are tightly clustered and tend to propagate small differences. This can be overwhelmed by small random errors. Thus, the double reciprocal plot (or Lineweaver-Burk-plot) is giving a non-uniform distribution of error. The Y-intercept in Lineweaver-Burk plot is equivalent to the reciprocal of the maximum velocity, $V_{\max }\left(1 \div \mathrm{V}_{\max }\right)$. Through the reciprocal of the maximum velocity, $V_{\max }\left(1 \div \mathrm{V}_{\max }\right)$; experimental error gets magnified. Similarly the Eadie-Hofstee plot has the disadvantage that velocity appears on both axes. Experimentally, this quantity is generally subject to more error than substrate concentration. With the aim to reduce the errors in Lineweaver-Burk plot and to magnify the mechanism of enzyme controlled biochemical reaction, the present attempt has been planned.

\section{Materials and Methods}

The credit of discovery of the circle passing through the significant points in, on and around the triangle goes to Karl Wilhelm von Feuerbach (30 May, 1800 - 12 March, 1834). He was mathematician (geometry as specialization) of Germany. According to Fraivert [10], in very first step, Karl Wilhelm von Feuerbach obtained the circle with six significant points on the triangle. The significant six points recognized by this circle are classified into two major groups. The first group of significant points recognized by the circle of Karl Wilhelm von Feuerbach include: the midpoints of the three sides of the triangle. The second group of significant points recognized by the circle of Karl Wilhelm von Feuerbach include: the foot point of each altitude of a triangle. Thus, three midpoints (each of three sides) and three points representing the foot points (each of three altitudes) constitute the significant six points recognized by the circle of Karl Wilhelm von Feuerbach [13]. Olry Terquem (16 June 1782 - 6 May 1862), a French mathematician made addition of three significant points in "significant recognized by the circle of Karl Wilhelm von Feuerbach". The third group of significant points (Olry Terquem's points) recognized by the circle of Karl Wilhelm von Feuerbach include: the midpoints of the line segment passing from each vertex to the orthocenter of the triangle [14]. This circle in geometry is recognized by various names of its discoverers and instances in the discovery. The names of this circle include: Feuerbach's circle, Euler's circle, Terquem's circle, the six points circle, the twelve points circle, the $n$-point circle, the medio-scribed circle, the mid circle or the circum-mid-circle [15], [16]. But the title "Nine-Point-Circle" deserve appreciable popularity and applicability. Altshiller-Court [2] listed geometrical properties for the "nine-point-circle". Accordingly, the "nine-point-circle" is passing through the "nine significant concyclic points" recognized by the triangle". The nine significant concyclic points on the "nine-point-circle" include: the midpoints of each side of the triangle; the foot point of each segment representing altitude and the midpoint of the line segment from each vertex to the point representing the orthocenter of the triangle. The steps to establish the bio-geometric model for the magnification of mechanism of enzyme involved reaction include the following: (a) establishment of a triangular form of the double reciprocal plot (or the Linewever-Burk-Plot) (line Y.1); (b) determination of mid points of three sides of the triangular form of double reciprocal plot; (c) determination of the foot point for each line segment forming the altitude of the triangular form of double reciprocal plot; (d) determination of the mid-point for each line segment passing from the vertex and orthocenter of the triangle; (e) determination of the center for five point circle for the triangle and (f) establishment of five point circle for the triangle.

\subsection{Establishment of a Triangular Form of the Linewever-Burk Plot (line Y.1)}

Fig. 3 is dealing with establishment of a triangular form of the Linewever-Burk Plot (line Y.1). The very first step in this reference is to obtain the triangular form of double reciprocal plot. The method described by Hubin et al. [17] was adopted in the present attempt. The double reciprocal plot (or 
Lineweaver-Burk-plot) (Fig. 2) is a graphical presentation of the numerical data on reciprocal of the substrate concentration $(1 \div \mathrm{S})$ and the reciprocal of reaction rate (velocity) $(1 \div \mathrm{V})$. In this graphical presentation, the $\mathrm{x}$ - axis is reserved for the inverse (reciprocal) of substrate concentration $(1 \div \mathrm{S})$ with suitable scale. The y-axis is reserved for the inverse (reciprocal) of reaction rate or velocity of enzyme involved reaction $(1 \div \mathrm{V})$ with suitable scale. Due to consideration of the both reciprocals $[(1 \div \mathrm{S})$ and $(1 \div \mathrm{V})]$, graph is also called as double reciprocal plot. Slope for double reciprocal plot (may also be called as regular form of "Lineweaver-Burk-plot") is $\left[\left(1 \div \mathrm{K}_{\mathrm{m}}\right) \div\left(1 \div \mathrm{V}_{\max }\right)=\left(\mathrm{K}_{\mathrm{m}} \div \mathrm{V}_{\max }\right)\right]$. The y- intercept for regular form of double reciprocal plot (may also be called as regular form of "Lineweaver-Burk-plot") is reciprocal of maximum velocity of enzyme controlled reaction, which corresponds to: $1 \div \mathrm{V}_{\max }$. Therefore, the mathematical equation for regular form of the double reciprocal plot is:

$\mathrm{Y} .1=\left[\left(\mathrm{K}_{\mathrm{m}} \div \mathrm{V}_{\max }\right)(1 \div \mathrm{S})\right]+\left[1 \div \mathrm{V}_{\max }\right]$.

Let's consider the $y$ - intercept of the line Y.1 as point, "A". The " $\mathrm{x}$ - coordinate" for " $\mathrm{A}$ " point is zero. The " $y$ - coordinate" of the "A" point is $\left(1 \div \mathrm{V}_{\max }\right)$ (Fig. 3). Likewise, the " $\mathrm{x}$ - coordinate" for the " $\mathrm{B}$ " point is one. The " $\mathrm{y}$ - co-ordinate" for " $\mathrm{B}$ " point is $\left(1 \div \mathrm{V}_{\max }\right)$. According to the mathematical equation for regular form of the double reciprocal plot $\left[\mathrm{Y} .1=\left(\mathrm{K}_{\mathrm{m}} \div \mathrm{V}_{\max }\right)(1 \div \mathrm{S})+\left(1 \div \mathrm{V}_{\max }\right)\right]$, when the reciprocal of substrate concentration $(1 \div \mathrm{S})$ is one, the value of "Y.1" become: $\left[\left(\mathrm{K}_{\mathrm{m}}+1\right) \div \mathrm{V}_{\max }\right]$. This point with the "x coordinate" of one and " $\mathrm{y}$ - coordinate" of $\left[\left(\mathrm{K}_{\mathrm{m}}+1\right) \div \mathrm{V}_{\max }\right]$ is designated as the point " $\mathrm{C}$ ". Therefore, the coordinates of the point "A", "B" and "C" can be written as: $\left[A\left(0,1 \div \mathrm{V}_{\max }\right)\right]$; $\left[\mathrm{B}\left(1,1 \div \mathrm{V}_{\max }\right)\right.$ and $[\mathrm{C}(1$, $\left.\left(\mathrm{K}_{\mathrm{m}}+1\right) \div \mathrm{V}_{\max }\right]$ respectively. The line segment, "AB" is going to serve as the base for the triangular form of double reciprocal plot. The line segment, "BC" is going to serve as the height for the triangular form of double reciprocal plot. The line segment, "AC" is going to serve as the hypotenuse for the triangular form of double reciprocal plot. That is to say, joining the point " $\mathrm{A}$ " to the point " $\mathrm{B}$ "; joining the point " $\mathrm{B}$ " to the point " $\mathrm{C}$ " and joining the point " $\mathrm{C}$ " to "A" yield a triangle. As appearing in Fig. 3, the triangle established is a right angled triangle. Measurement of one of the angle in a "right angled triangle" corresponds to ninety degree. The figure thus obtained is titled as, "Triangular form of double reciprocal plot in enzyme biochemistry". This triangular form of double reciprocal plot (Fig. 3) is now eligible for application of "Nine point circle".

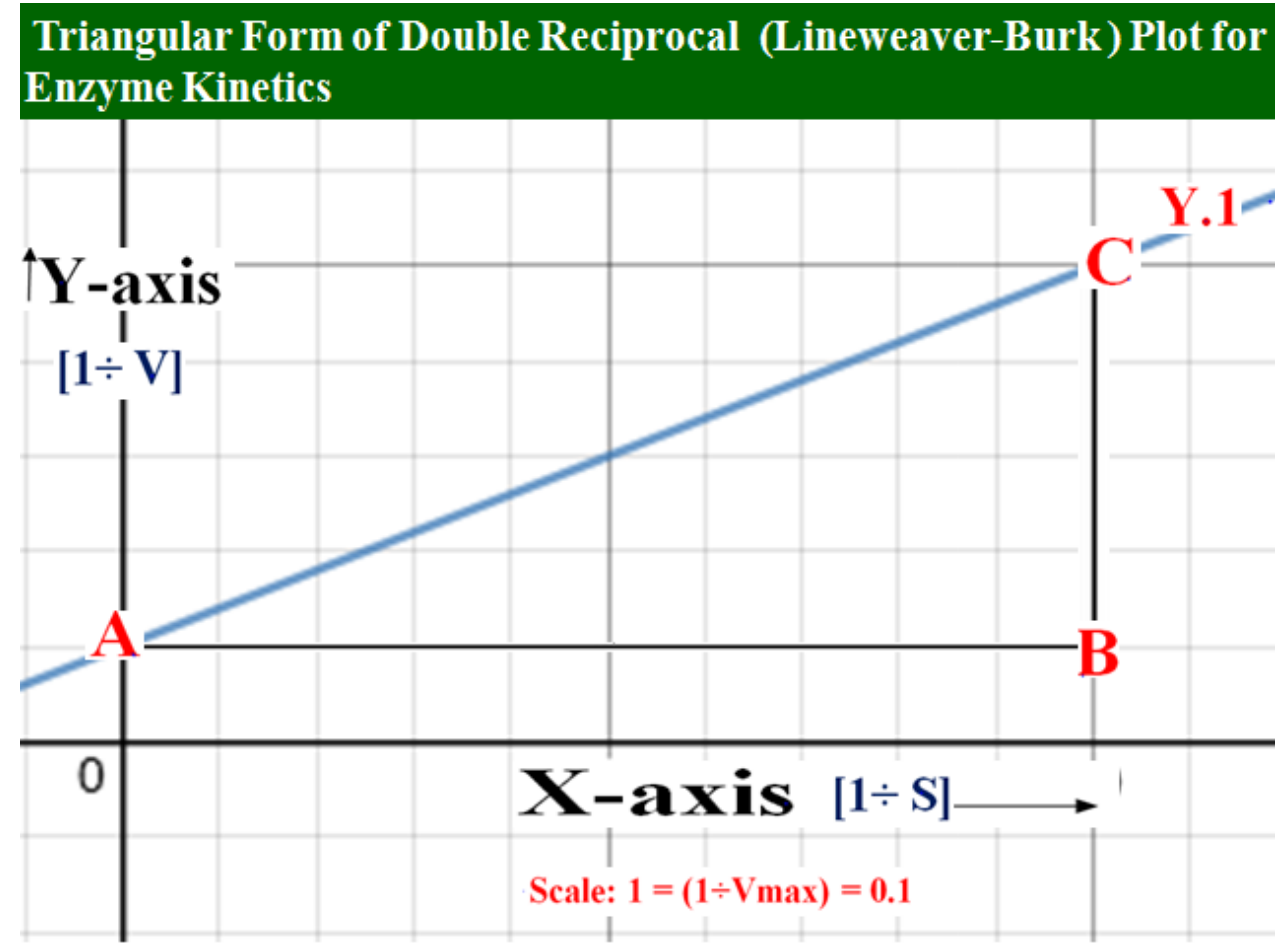

Fig. 3 The triangular form of double reciprocal (Lineweaver-Burk) plot

\subsection{Determination of mid points of three sides of the triangular form of double reciprocal plot}

The attempt towards the determination of the mid points of the three sides of geometric triangle by [16], [18] is similar to the determination of the geometric centroid (center of mass) of a triangle. The centroid is point of intersection of three medians in a triangle. This may be the reason for recognizing the centroid as the median point of a triangle. The centroid of a triangle is with equivalent center function. In geometry, the median for triangle is defined as "line segment joining the vertex point of a triangle to the midpoint of 
the opposite side". The line segment representing the median has to bisect the side of triangle into two equal sub segments.

The Fig. 4 is dealing with the three median lines (Y.2; Y.3 and Y.4) for the determination of mid points of the triangular form of double reciprocal plot $(\triangle \mathrm{ABC})$. The slope for the line Y.2; Y3 and Y.4 respectively correspond to: $\left[-\left(\mathrm{K}_{\mathrm{m}} \div \mathrm{V}_{\max }\right)\right] ;\left[\left(\mathrm{K}_{\mathrm{m}} \div 2 \mathrm{~V}_{\max }\right)\right]$ and $\left[\left(2 \mathrm{~K}_{\mathrm{m}} \div \mathrm{V}_{\max }\right)\right]$. The y-intercept for the line Y.2; Y3 and Y.4 respectively correspond to: $\left[\left(\mathrm{K}_{\mathrm{m}}+1\right) \div\left(\mathrm{V}_{\max }\right)\right] ;\left[\left(1 \div \mathrm{V}_{\max }\right)\right]$ and $\left[-\left(\mathrm{K}_{\mathrm{m}}-1\right) \div\left(\mathrm{V}_{\max }\right)\right]$.

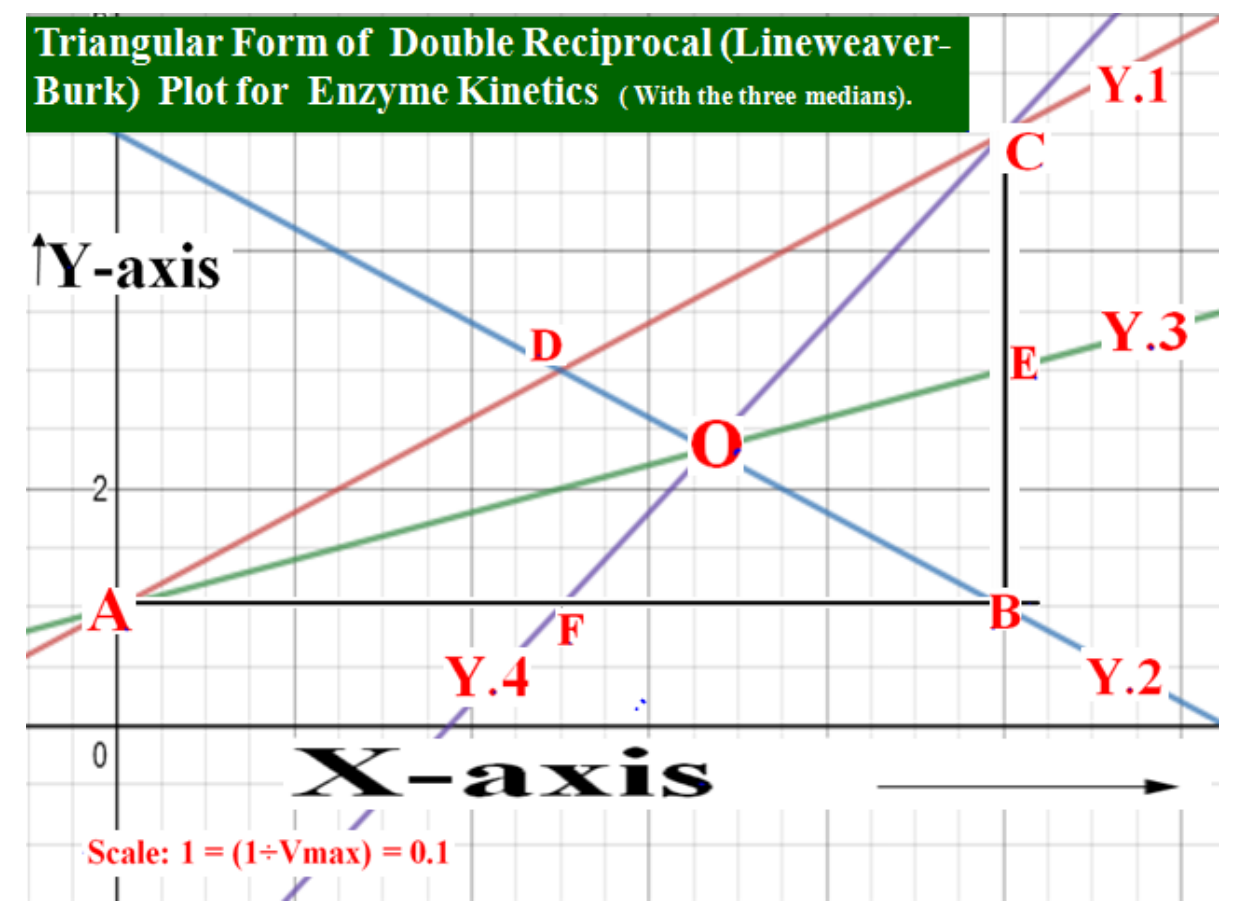

Fig. 4 The triangular form of double-reciprocal-plot (Lineweaver-Burk-plot) (with the three medians)

Therefore, the equation of the line Y.2; line Y.3 and line Y.4 respectively corresponds to:

$$
\begin{aligned}
\mathrm{Y} .2 & =\left[-\left(\mathrm{K}_{\mathrm{m}} \div \mathrm{V}_{\max }\right)(1 \div \mathrm{S})\right]+\left[\left(\mathrm{K}_{\mathrm{m}}+1\right) \div\left(\mathrm{V}_{\max }\right)\right] . \\
\mathrm{Y} .3 & =\left[\left(\mathrm{K}_{\mathrm{m}} \div 2 \mathrm{~V}_{\text {max }}\right)(1 \div \mathrm{S})\right]+\left[\left(1 \div \mathrm{V}_{\max }\right)\right] . \\
\mathrm{Y} .4 & =\left[2\left(\mathrm{~K}_{\mathrm{m}} \div \mathrm{V}_{\text {max }}\right)(1 \div \mathrm{S})\right]+\left[-\left(\mathrm{K}_{\mathrm{m}}-1\right) \div\left(\mathrm{V}_{\max }\right)\right] .
\end{aligned}
$$

In a triangular form of "double-reciprocal-plot" (Fig. 4), the line segment "BD" (belongs to line Y.2); the segment "AE" (belongs to line Y.3) and the segment "CF" (belongs to line Y.4) are the three medians. The point, "O" is the point of intersection of three medians (segment "BD", segment "AE" and segment "CF"). The point, "O" is centroid of triangular form of double reciprocal plot ( $\triangle \mathrm{ABC}$ ) (Fig. 4).

The centroid is a point of concurrency of triangular form of "Lineweaver-Burk-plot" ("doublereciprocal-plot") for enzyme kinetics [19]. It is the point of saturation of the enzyme substrate reaction. The distinguishing features (geometric distinguishing features) of centroid of a triangle include:

(a) It is the point of intersection of the three medians in a triangle;

(b) It is one of the significant points in a triangle exhibiting concurrency;

(c) It is always located inside the triangle;

(d) It divides each median in a ratio of 2:1.; and

(e) It will always be $2 / 3$ of the way along any given median.

The point "O" in Fig. 4 is representing centroid of the triangular form of double reciprocal plot $(\triangle \mathrm{ABC})$. Attempt towards the establishment of the three medians is helping not only for knowing the point of centroid but also for the determination of mid points of three sides of the triangular form of double reciprocal plot. The point " $F$ " is thus the mid-point of segment "AB". The co-ordinates of the point "A", point "B" and point " $F$ " are known. The coordinates of the point " $A$ ", the point "B" and the point " $F$ " can be written as: $\left[\mathrm{A}\left(0,1 \div \mathrm{V}_{\max }\right)\right] ;\left[\mathrm{B}\left(1,1 \div \mathrm{V}_{\max }\right)\right]$ and $\left[\mathrm{F}\left(0.5,\left(1 \div \mathrm{V}_{\max }\right)\right]\right.$ respectively. The point "E" constitutes the mid-point of the segment "BC". It means, the coordinates of the point "E" can be mentioned as: $\mathrm{E}\left[\left(1,\left(\mathrm{~K}_{\mathrm{m}}+2\right) \div 2 \mathrm{~V}_{\max }\right]\right.$. The point "D" constitutes the mid-point of the segment "AC", the hypotenuse of the triangular form of double reciprocal plot. Therefore, the co-ordinates of the point " $D$ " can be written as: $\mathrm{D}\left[0.5,\left(\mathrm{~K}_{\mathrm{m}}+2\right) \div 2 \mathrm{~V}_{\max }\right]$. 


\subsection{Determination of foot point of each line segment forming the altitude of a triangular form of double reciprocal plot}

In a triangle, foot point of altitude-line-segment is the point of intersection of the "line-segment representing the side" with the "altitude line segment". Altitude is perpendicular to the "line-segment representing the side". The base-line-segment in a triangle is a side opposite the point of vertex. The linesegment in a triangle containing the opposite side is considered as the "extended base of the altitude". Foot of altitude can also be defined as, "the point of intersection of the extended base and the altitude". Many a times the word "altitude" alone is considered to explain the length of the "altitude-line-segment" in a triangle. Therefore, the distance between the extended base and the vertex constitute the "Altitude". Dropping the altitude is nothing but the "process of establishment of perpendicular line segment passing from the vertex of a triangle to the foot". Altitude segment is perpendicular to the opposite side of each vertex of a triangle. Many a time, in geometry, altitudes serve for the purpose of computation of area of a triangle. The area of the triangle is one half of the product of length of base and length of altitude. Significant feature of a triangles lies in occurrence of the shortest side perpendicular to the longest altitude. Mitchell [20] established the relation between the altitudes and the sides of the triangle through trigonometric functions. There is only one significant point in a triangle serving for intersection of three altitudes. In geometrical language, the point of intersection of three altitudes constitutes the most significant point called as: Orthocenter of a triangle. If a triangle is acute (does not have an angle greater than or equal to a right angle), the orthocenter always lie inside a triangle. If one angle of a triangle is a right angle, the point of orthocenter coincides with the vertex at that right angle [12], [21].

The Fig. 5 deals with three median lines (Y.2; Y.3 and Y.4); altitudes (segment AB, Segment CB and segment BG); centroid (point "O") and orthocenter (point "B"). In comparison with Fig. 4, there is additional line (Y.5) in Fig. 5. [- $\left.\left(\mathrm{V}_{\max } \div \mathrm{K}_{\mathrm{m}}\right)\right]$ is the slope for the line - $\mathrm{Y} .5$. The $\left[\left(\mathrm{V}_{\max }{ }^{2}+\mathrm{K}_{\mathrm{m}}\right) \div\left(\mathrm{V}_{\max } \cdot \mathrm{K}_{\mathrm{m}}\right)\right]$ is the $\mathrm{y}$ - intercept for the line Y.5. The geometric equation for the line-Y.5 correspond to:

$\mathrm{Y} .5=\left[-\left(\mathrm{V}_{\max } \div \mathrm{K}_{\mathrm{m}}\right)(1 \div \mathrm{V})\right]+\left[\left(\mathrm{V}_{\max }^{2}+\mathrm{K}_{\mathrm{m}}\right) \div\left(\mathrm{V}_{\max } \cdot \mathrm{K}_{\mathrm{m}}\right)\right]$.

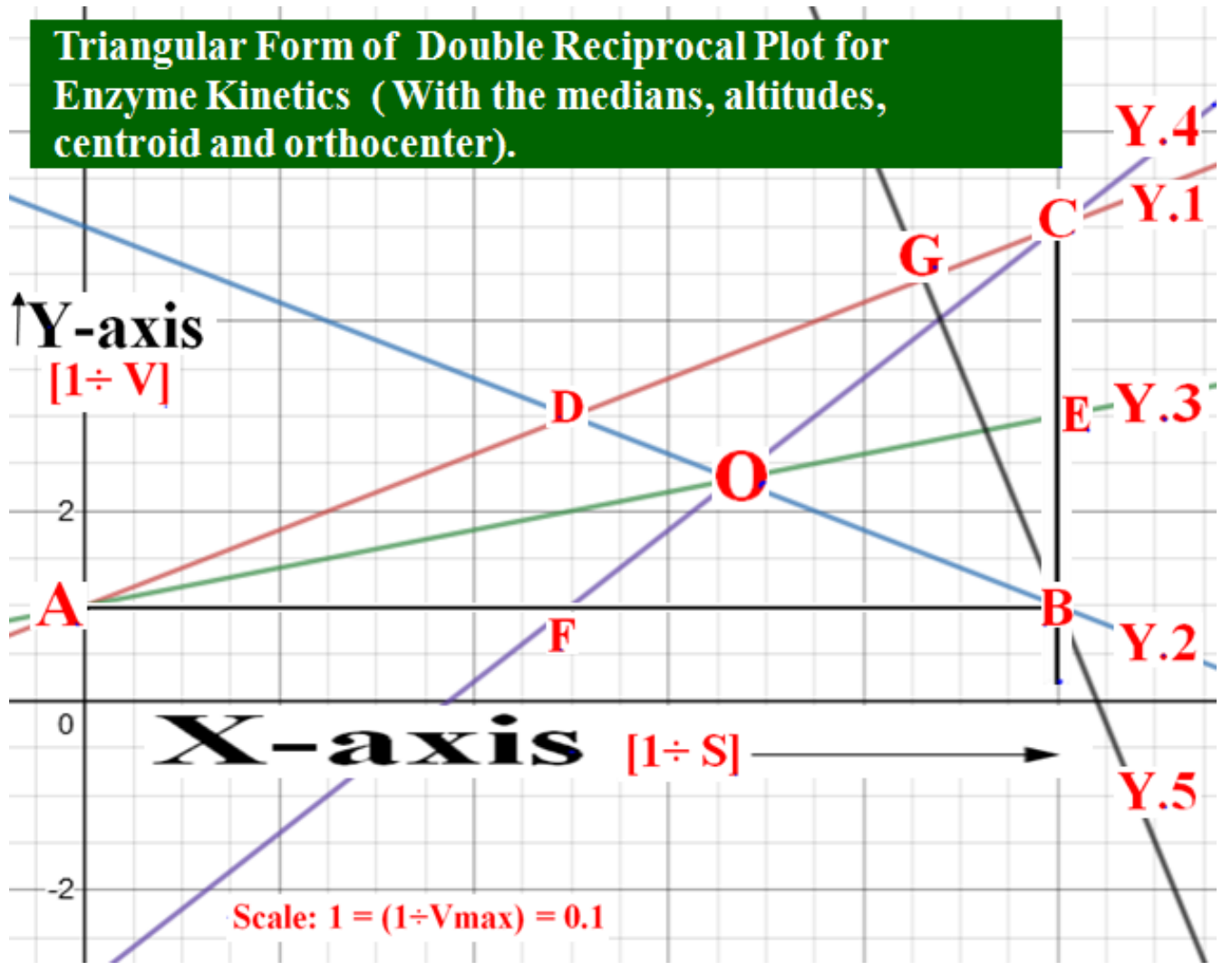

Fig. 5 The triangular form of double-reciprocal-plot (Lineweaver-Burk-plot) (with the medians, altitudes, centroid and orthocenter).

In Figs. 4 and 5, the line-segment "AB" constitutes altitude dropped from the vertex point " $A$ " on the base segment "BC". In Figs. 4 and 5, the line-segment "CB" constitutes altitude dropped from the vertex point " $C$ " on the base segment "AB". In Fig. 5, the line-segment "BG" constitutes altitude dropped from the vertex point "B" on the base segment "AC". The three line-segments: AB; BC and BG (the three 
altitudes in a triangle "ABC") are intersecting in a single point: "B". The point "B" in the right angled triangle $(\triangle \mathrm{ABC})(\mathrm{Fig} .5)$ is the intersection of the three altitudes (line-segment $\mathrm{AB}$, line-segment $\mathrm{CB}$ and the line-segment $\mathrm{BG}$ ). The point " $\mathrm{B}$ " in the triangular form of double reciprocal plot (right-angled triangle $\triangle \mathrm{ABC}$ ) (Fig. 5) is eligible for designation as the orthocenter [19].

Attempt towards establishment of altitude-segments is helping not only for knowing the point of orthocenter but also for the determination of foot points of three altitudes of the triangular form of double reciprocal plot. The point "B" in Fig. 5 is the foot point for the altitude segment "AB" as well as the altitude segment "CB". In a right-angled-triangle, the feet (base-points) of two of the altitude-segments coincide with the point of vertex of the right angle. In addition, the feet (base-points) of two of the mid-points of segments drawn from the vertices to the orthocenter coincide with the mid-points of the legs (side segments forming right angle in a triangle) [22]. The point "G" in Fig. 5 is the foot point for the altitude segment "GB".

In a triangle, the altitude segment is perpendicular to the line-segment containing the base. The baseline-segment of triangle is the side opposite the point of vertex. In geometry, the line-segment containing the opposite side is termed the extended base of the altitude. Foot point or base point for altitude is the point of intersection of the extended base and the altitude-segment. Many a times the word "altitude" is used to denote the length of the altitude. Altitude is the distance between the extended base and the vertex. Dropping the altitude is nothing but the process of drawing the altitude from the vertex point to the foot point. The concept of the "Altitude" of can be utilized for the computation of the area of a triangle. The area of the triangle is one half of the product of length of base and length of altitude. Significant feature of triangle lies in occurrence of the shortest side perpendicular to the longest altitude. Mitchell [20], established the relation between the altitudes and the sides of the triangle through trigonometric functions. In a triangle, there is only one point representing intersection of three altitudes. In a triangle, the intersection point of three altitudes constitutes the point of orthocenter. If the triangle is acute (does not have an angle greater than or equal to a right angle), the point of orthocenter lies inside the triangle. In a triangle, if one of the angle is a right angle, the orthocenter point coincides with the vertex point at the right angle [12].

\subsection{Determination of midpoint of the line segment from each vertex of the triangle to the point representing the orthocenter of the triangular form of double reciprocal plot}

In a triangle, the orthocenter point is the point of concurrence of the three altitudes. The orthocenter is the only one point that has no exact analogue for arbitrary higher dimensional simplexes, for spherical and hyperbolic triangles, or for triangles in normed planes. According to Jankvist [23] and Khyade et al. [19], of all the traditional centers of a triangle, the orthocenter is probably the one that attracted the most of attention of researchers.

The Fig. 5 is going to serve the purpose of determination of mid-point of the line-segment from each vertex to the point representing the orthocenter of the triangular form of double reciprocal plot. The segment "AB" in a triangle "ABC" (Fig. 5) is passing from the "A" point (vertex point-A) to the point "B", representing the orthocenter of the triangular form of double reciprocal plot $(\triangle \mathrm{ABC})$. The point " $\mathrm{F}$ " is the mid-point of the segment "AB" in a triangle "ABC" (Fig. 5). Likewise, segment "CB" in a triangle "ABC" (Fig. 5) is passing from the vertex point " $\mathrm{C}$ " to the point " $\mathrm{B}$ ", representing the orthocenter of the triangular form of double reciprocal plot $(\triangle \mathrm{ABC})$. The point " $\mathrm{E}$ " is the mid-point of the segment "CB" in a triangle "ABC" (Fig. 5). Thus, the point "E" and the point "F" are the midpoints of the line-segment from each vertex of the triangle to the point representing the orthocenter of the triangular form of double reciprocal plot.

\subsection{Determination of center for the circle in expectation of the principles of "Nine point circle" in triangular form of double reciprocal plot}

According to Kocik and Solecki [15], the center of nine point circle is the "Nine Point Center of the Triangle" [21]. Posamentier [24] opined that, the radius of circumcircle of a triangle is twice the radius of that triangle's nine-point circle. The results of the earlier attempts (sections $2.1-2.3$ ) include the yield of triangular form; mid points of the three sides; feet of altitudes and the mid-point of segment passing from vertex to orthocenter of triangular form of double reciprocal plot (which are the fundamental requirements of geometrical nine point circle) (Fig. 6). The mid points of the three sides of triangular form of double reciprocal plot include: D, E and F. The feet points of altitudes in a triangular form double reciprocal plot include: B and G. The mid-point of segment passing from vertex to orthocenter of triangular form of double reciprocal plot include: $\mathrm{E}$ and $\mathrm{F}$. Thus, the five significant points of triangular form of double reciprocal plot include: B, D, E, F and G (Fig. 6). Let us proceed for the attempt on determination of center for "Nine point circle" in triangular form of double reciprocal plot. 


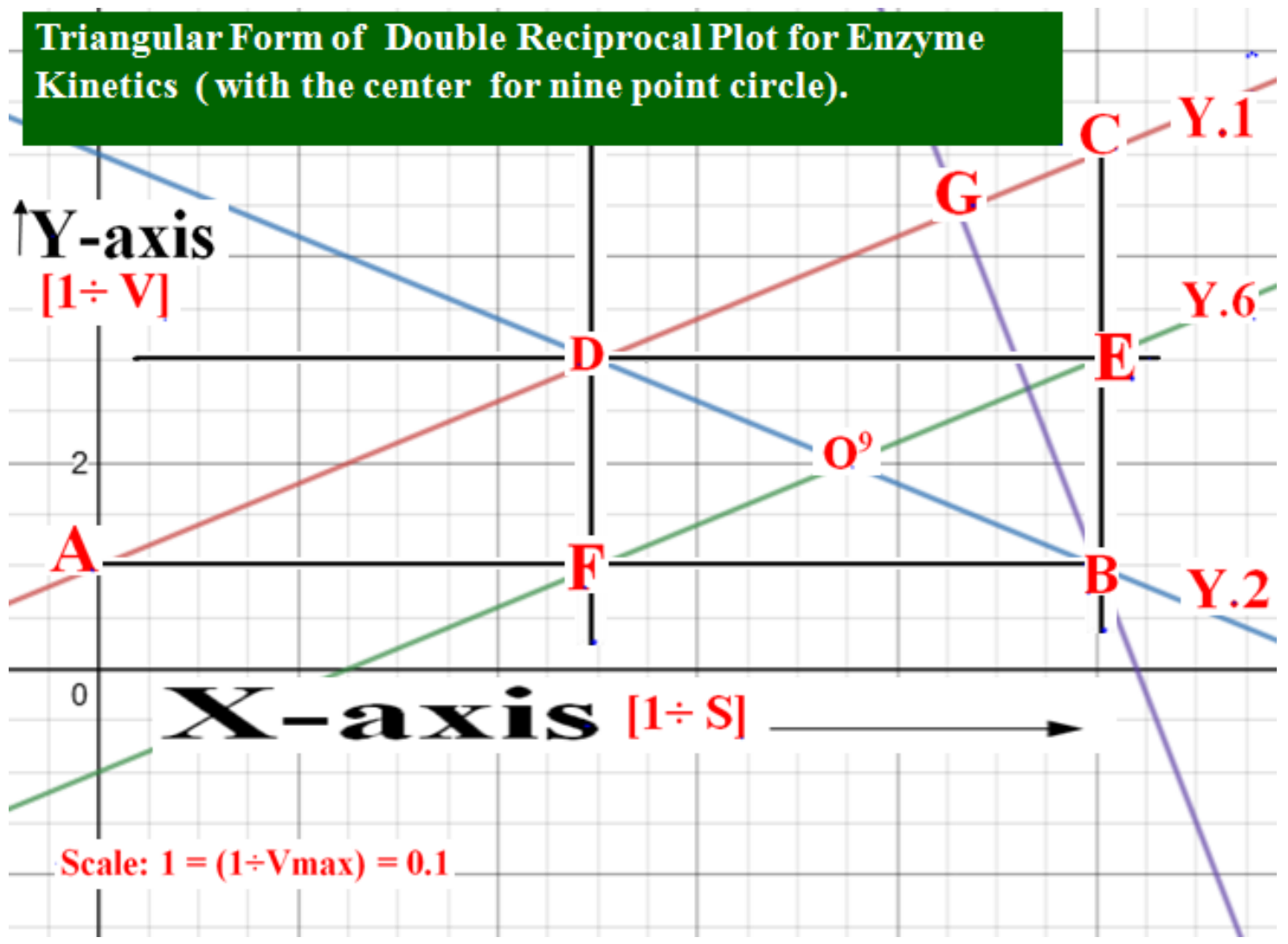

Fig. 6 The triangular form of double reciprocal (Lineweaver-Burk) plot (with the center for five point circle)

Fig. 6 is dealing with the determination of point of center for the "Nine-Point-Circle" for a triangle "ABC" resulted as a "triangular form of double-reciprocal-plot of kinetics for the enzymes. The method used for the determination of point of center for the nine point circle in present attempt belongs to Ozdemir et al. [1]. In Fig. 6, let us consider the segment DE and segment EF. Now imagine their midpoints and their perpendicular bisectors (a line perpendicular to each respective segment through its midpoint). It is very much clear in a triangle "ABC", in Fig.6, the center for expected circle in the attempt is the point of intersection of the perpendicular bisector line-segments. Let's label this center $\mathrm{O}^{9}$. The lengths of segment $O^{9} \mathrm{~F}$; segment $O^{9} B$; segment $O^{9} E$; segment $O^{9} D$ and segment $\mathrm{O}^{9} \mathrm{D}$ in Fig. 5 are equal and representing the radius of expected circle. The center for expected circle can also be determined through the line equations. In Fig. 5 and 6; the segment FB, the segment BE, the segment DE and the segment DF are forming the rectangle. The segment $\mathrm{BD}$ and segment $\mathrm{EF}$ are forming the diagonals, intersecting at the center of rectangle (as well as the expected circle).The segment BD and segment EF belong to the line Y.2 and Y.6 respectively. The geometrical (or mathematical) equation for the line Y.2 is:

$\mathrm{Y} .2=\left[-\left(\mathrm{K}_{\mathrm{m}} \div \mathrm{V}_{\max }\right)(1 \div \mathrm{S})\right]+\left[\left(\mathrm{K}_{\mathrm{m}}+1\right) \div\left(\mathrm{V}_{\max }\right)\right]$.

Let's proceed for the geometrical (or mathematical) equation for the line Y.6. In Figs. 5 and 6, the line Y.6 is parallel to the line representing the real form of double-reciprocal-plot (Lineweaver-Burk-plot) (Y.1 line). Therefore, the slope for the line Y.1 and the line Y.6 is one and the same. The slope for the line Y.1 and the line Y.6 corresponds to: $\left[\left(\mathrm{K}_{\mathrm{m}} \div \mathrm{V}_{\max }\right)\right]$. In the Figs. 6 and 7, the point "F" is on the line Y.6. The $\mathrm{x}$ and $y$ - co-ordinates of the point "F" are known. $(1 \div 2)$ and $\left(1 \div \mathrm{V}_{\max }\right)$ are respectively the $\mathrm{x}$ - and $\mathrm{y}$ - coordinates of the point "F". 


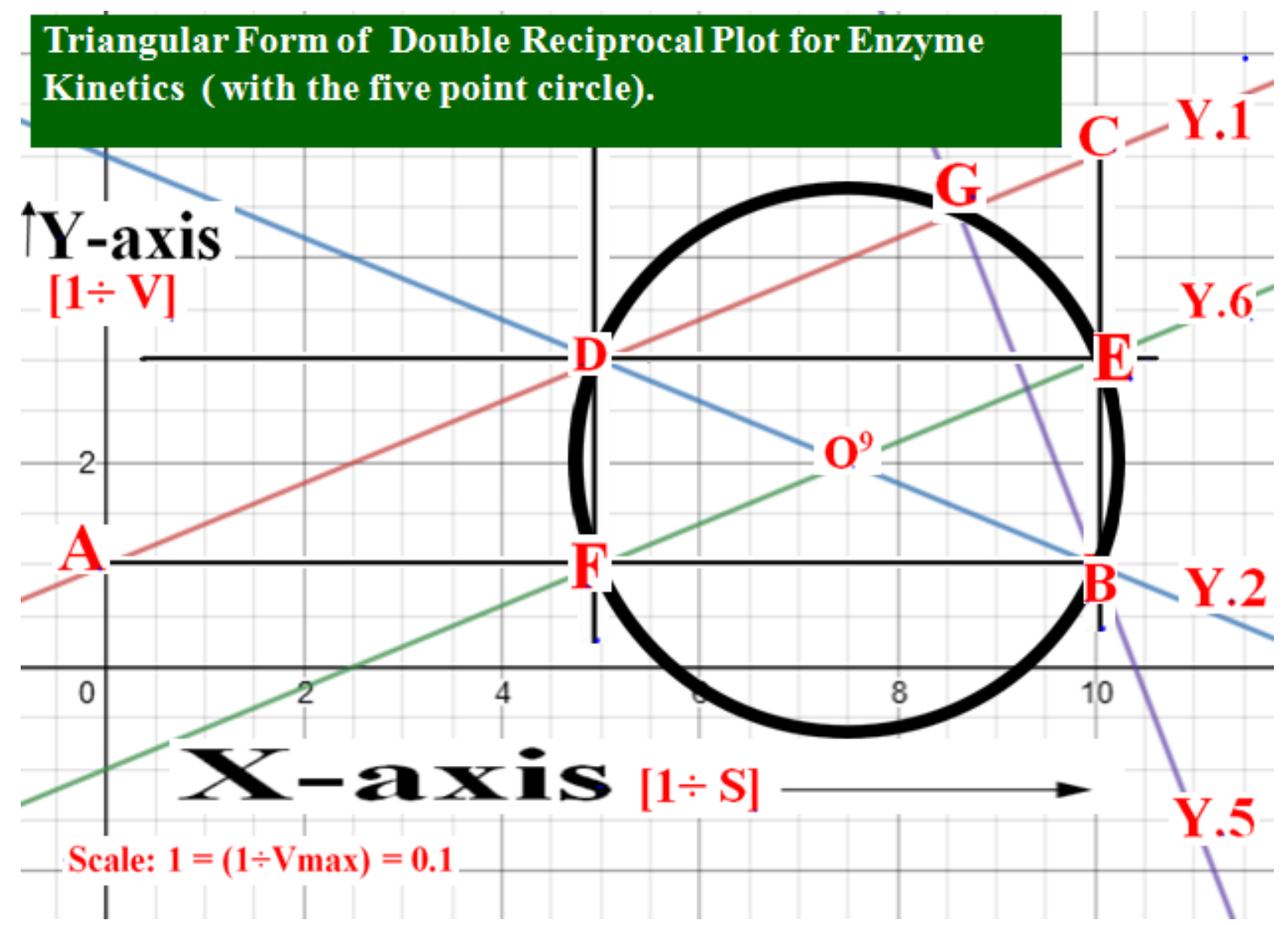

Fig. 7 The "five-point-circle" for triangular form of double-reciprocal-plot (Lineweaver-Burk-plot)

The $\mathrm{x}$ - and $\mathrm{y}$ - co-ordinates of the point " $\mathrm{F}$ " are going to serve for determination of intercept of the line Y.6 on the $y$ - axis. For this purpose, let's put the " $X$ " value and "Y" value of the point " $F$ " in the expected equation for the line Y.6 as:

Y.6. $=\frac{\mathrm{m}}{1} \times \frac{\mathrm{x}}{1}+\frac{\mathrm{C}}{1}$.

Replacing "X" by $(1 \div 2)$ and "y" by $\left(1 \div \mathrm{V}_{\max }\right)$,

Y.6. $=\frac{\mathrm{K}_{\mathrm{m}}}{\mathrm{V}_{\max }} \times \frac{1}{2}+\frac{\mathrm{C}}{1}=\frac{1}{\mathrm{~V}_{\max }}$.

Simplifying,

$\frac{C}{1}=\frac{1}{\mathrm{~V}_{\max }}-\frac{\mathrm{K}_{\mathrm{m}}}{\mathrm{V}_{\max }} \times \frac{1}{2}=\frac{2-\mathrm{K}_{\mathrm{m}}}{2 \cdot \mathrm{V}_{\max }}$

$\mathrm{C}=-\left[\left(\mathrm{K}_{\mathrm{m}}-2\right) \div\left(2 \mathrm{~V}_{\max }\right)\right]$

The line equation for Y.6 is:

Y.6. $=\frac{\mathrm{K}_{\mathrm{m}}}{\mathrm{V}_{\max }} \times \frac{1}{\mathrm{~s}}+\frac{2-\mathrm{K}_{\mathrm{m}}}{2 . \mathrm{V}_{\max }}$.

The intersection of the line Y.2 and Y.6 is going to yield the center of rectangle BEDF (as well as the expected circle); thus:

$\mathrm{Y} .2=\mathrm{Y} .6$

$\frac{-\mathrm{K}_{\mathrm{m}}}{\mathrm{V}_{\max }} \times \frac{1}{S}+\frac{\mathrm{K}_{\mathrm{m}}+1}{\mathrm{~V}_{\max }}=\frac{\mathrm{K}_{\mathrm{m}}}{\mathrm{V}_{\max }} \times \frac{1}{S}+\frac{2-\mathrm{K}_{\mathrm{m}}}{2 \cdot \mathrm{V}_{\max }}$.

By changing the sides and simplification:

$\frac{\mathrm{K}_{\mathrm{m}}+1}{\mathrm{~V}_{\max }}-\frac{2-\mathrm{K}_{\mathrm{m}}}{2 \cdot \mathrm{V}_{\max }}=\frac{2 \mathrm{~K}_{\mathrm{m}}}{\mathrm{V}_{\max }} \times \frac{1}{S}$

$\frac{2 \mathrm{~K}_{\mathrm{m}}+2-2+\mathrm{K}_{\mathrm{m}}}{2 \mathrm{~V}_{\max }}=\frac{2 \mathrm{~K}_{\mathrm{m}}}{\mathrm{V}_{\max }} \times \frac{1}{\mathrm{~S}}$,

$\frac{3 \mathrm{~K}_{\mathrm{m}}}{2 \mathrm{~V}_{\max }}=\frac{2 \mathrm{~K}_{\mathrm{m}}}{\mathrm{V}_{\max }} \times \frac{1}{\mathrm{~S}}$, 
$\frac{3 \mathrm{~K}_{\mathrm{m}}}{2 \mathrm{~V}_{\max }} \times \frac{\mathrm{V}_{\max }}{2 \mathrm{~K}_{\mathrm{m}}}=\frac{1}{\mathrm{~S}}$,

$\frac{3}{4}=\frac{1}{s}$.

Equation (17) clearly indicates that, the " $\mathrm{x}$ - coordinate" of the "point of intersection" of the line Y.2 and the line Y.6 is $[(3 \div 4)]$.The "y- coordinate" for the "point of intersection" of the line Y.2 and the line Y.6 is going to yield through replacing the value of "X $=(1 \div \mathrm{S})$ " as $[(3 \div 4)]$ in either equation of line Y.2 or the equation of line Y.6.

Let's replace the value of $\frac{1}{s}$ in equation (16) by $[(3 \div 4)]$, the equation of the line Y.6 becomes:

Y.6. $=\frac{\mathrm{K}_{\mathrm{m}}}{\mathrm{V}_{\max }} \times \frac{3}{4}+\frac{2-\mathrm{K}_{\mathrm{m}}}{2 \cdot \mathrm{V}_{\max }}$

by simplification,

Y.6. $=\frac{\mathrm{K}_{\mathrm{m}}+4}{4 \mathrm{~V}_{\max }}$.

The " $y$ - coordinate" for the point of intersection of the line Y.2 and the line Y.6 is $\left[\left(K_{m}+4\right) \div\left(4 V_{\max }\right)\right]$. The segment BD and segment EF (in Figs. 5, 6 and 7) are forming the diagonals, intersecting at the center of rectangle (as well as the expected circle). Thus, the $\mathrm{x}$ - coordinate for the center of expected circle in the attempt corresponds to: $[(3 \div 4)]$. And, the $\mathrm{y}$ - coordinate for the center of expected circle in the attempt corresponds to $\left[\left(\mathrm{K}_{\mathrm{m}}+4\right) \div\left(4 \mathrm{~V}_{\max }\right)\right]$.

\subsection{Establishment of the "Five Point Circle"}

According to Wells [18], the center of nine point circle is the "Nine Point Center of the Triangle". The radius of circumcircle of a triangle is twice the radius of that triangle's nine-point circle [24]. A circle is a geometrical figure consisting of all points placed at equal distance from a given point, the center. The circle may also be considered as the curve traced out by a point that moves in a plane (provided, its distance from a given point: center is constant). The radius is the distance between any point of the circle and the center. The geometry established by Euclid (mathematician of Greece) and, in particular, the "Euclidean plane" is the foundation for construction of the five point circle for the triangle constructed in the "double-reciprocalplot" of the kinetics of enzymes. Being a simple closed diagram, the circle divides the plane into interior part and exterior parts (the two regions). The segment BD and segment EF (in Figs. 6 and 7) are forming the diagonals, intersecting at the center of rectangle: BEDF (as well as the expected circle). The point "O" in Figs. 6 and 7 is representing the center for circumscribed circle for the rectangle: BEDF. The points present on same circle are designated as "concyclic-points" or "cocyclic points". In Figs. 6 and 7, the line Y.2 (containing segment BD) and the line Y.6 (containing segment EF) are intersecting at the point, "O". Geometrically, the four points: B, D, E, F are said to be concyclic (provided, BO.OD = EO.OE). Thus, the segment BO; segment DO; segment EO and segment FO in the Figs. 6 and 7 are the radii for expected circle. The $\mathrm{x}$ - coordinate for the center of expected circle in the attempt corresponds to: $[(3 \div 4)]$. And, the $y$ - coordinate for the center of expected circle in the attempt corresponds to: $\left[\left(\mathrm{K}_{\mathrm{m}}+4\right) \div\left(4 \mathrm{~V}_{\max }\right)\right]$. The segment OB; segment OE; segment OD and segment OF in the Figs. 6 and 7 are the radii for expected circle.

\section{Results and Discussion}

The five point circle for the triangle constructed through the use of "double-reciprocal-plot" for the kinetic parameters of enzymes (in present attempt) is exhibiting the properties of circle in Euclidean geometry, and, in particular, the Euclidean plane. The results of the attempts in material and methods (sections $2.1-2.3$ ) include: the yield of triangular form; mid points of the sides of a triangle; foot point (or base point) for each altitude and the mid-point for segment passing from vertex to orthocenter of triangular form of double reciprocal plot (which are the fundamental requirements of geometrical nine point circle) (Figs. 4 and 5). The mid points of the three sides of triangular form of double reciprocal plot include: D, E and $\mathrm{F}$. The feet points of altitude segments in a triangular form double reciprocal plot include: $\mathrm{B}$ and $\mathrm{G}$. The mid-point of segment passing from vertex to orthocenter of triangular form of double reciprocal plot include: $\mathrm{E}$ and $\mathrm{F}$. Thus, the five significant points of triangular form of double reciprocal plot include: $\mathrm{B}$, D, E, F and G (Figs. 4 and 5).

In biochemistry, the five point circle can be constructed for triangle (in "double-reciprocal-plot" or "Lineweaver-Burk-plot" for the kinetic parameters of enzymes). This circle is exhibiting significant concyclic points (five in number). These significant concyclic points (five in number) can be defined from the triangle (in "double-reciprocal-plot" or "Lineweaver-Burk-plot" for the kinetic parameters of 
enzymes). These significant concyclic points (five in number) of the circle in present attempt include: the mid-point of each side (Base: segment "AB"; Height: segment "BC" and Hypotenuse: segment "AC") of the triangle (in "double-reciprocal-plot" or "Lineweaver-Burk-plot" for the kinetic parameters of enzymes); the point of right angle vertex and the point of intersection of the line perpendicular to real form of double-reciprocal-plot (Lineweaver-Burk-plot) and passing through the right angle vertex.

The mid-point of base segment and mid-point of height segment resulted in the attempt are also serving as the mid-point of the segment passing from vertex to the orthocenter.

The five significant points resulted on circle include: $\mathrm{B}, \mathrm{D}, \mathrm{E}, \mathrm{F}$ and $\mathrm{G}$. The $\mathrm{x}$-coordinate and $\mathrm{y}$ coordinate of "B"-point are: 1 and $\left(1 \div \mathrm{V}_{\max }\right)$ respectively. The $\mathrm{x}$ - coordinate and y-coordinate of " $\mathrm{D}$ "point are: $[(1 \div 2)]$ and $\left.\left[\left(\mathrm{K}_{\mathrm{m}}+2\right) \div 2 \mathrm{~V}_{\max }\right)\right]$ respectively. The $\mathrm{x}$ - coordinate and y-coordinate of "E"-point are: $[(1 \div 1)]$ and $\left.\left[\left(\mathrm{K}_{\mathrm{m}}+2\right) \div 2 \mathrm{~V}_{\max }\right)\right]$ respectively. The $\mathrm{x}$ - coordinate and $\mathrm{y}$-coordinate of "F"-point are: $(1 \div 2)$ and $\left(1 \div \mathrm{V}_{\max }\right)$ respectively. The $\mathrm{x}$ - coordinate and y-coordinate of " $\mathrm{G}$ "-point are: $\left[\left(\mathrm{V}_{\max }{ }^{2}\right) \div\left(\mathrm{V}_{\max }{ }^{2}+\mathrm{K}_{\mathrm{m}}{ }^{2}\right]\right.$ and $\left[\mathrm{K}_{\mathrm{m}}\left(\mathrm{V}_{\max }{ }^{2}+\mathrm{K}_{\mathrm{m}}\right)+\mathrm{V}_{\max }{ }^{2}\right] \div\left[\left(\mathrm{V}_{\max }{ }^{2}+\mathrm{K}_{\mathrm{m}}{ }^{2}\right) \mathrm{V}_{\max }\right]$ respectively. The $\mathrm{x}$ - coordinate and y-coordinate of point of center $\left(\mathrm{O}^{9}\right)$ of a circle in present attempt are: $[(3 \div 4)]$ and $\left[\left(\mathrm{K}_{\mathrm{m}}+4\right) \div\left(4 \mathrm{~V}_{\max }\right)\right]$ respectively.

The resulted circle is titled as, "Five Point Circle for the triangle (in "double-reciprocal-plot" or "Lineweaver-Burk-plot" for the kinetic parameters of enzymes) in Enzyme-Biochemistry" as shown in Fig. 8.

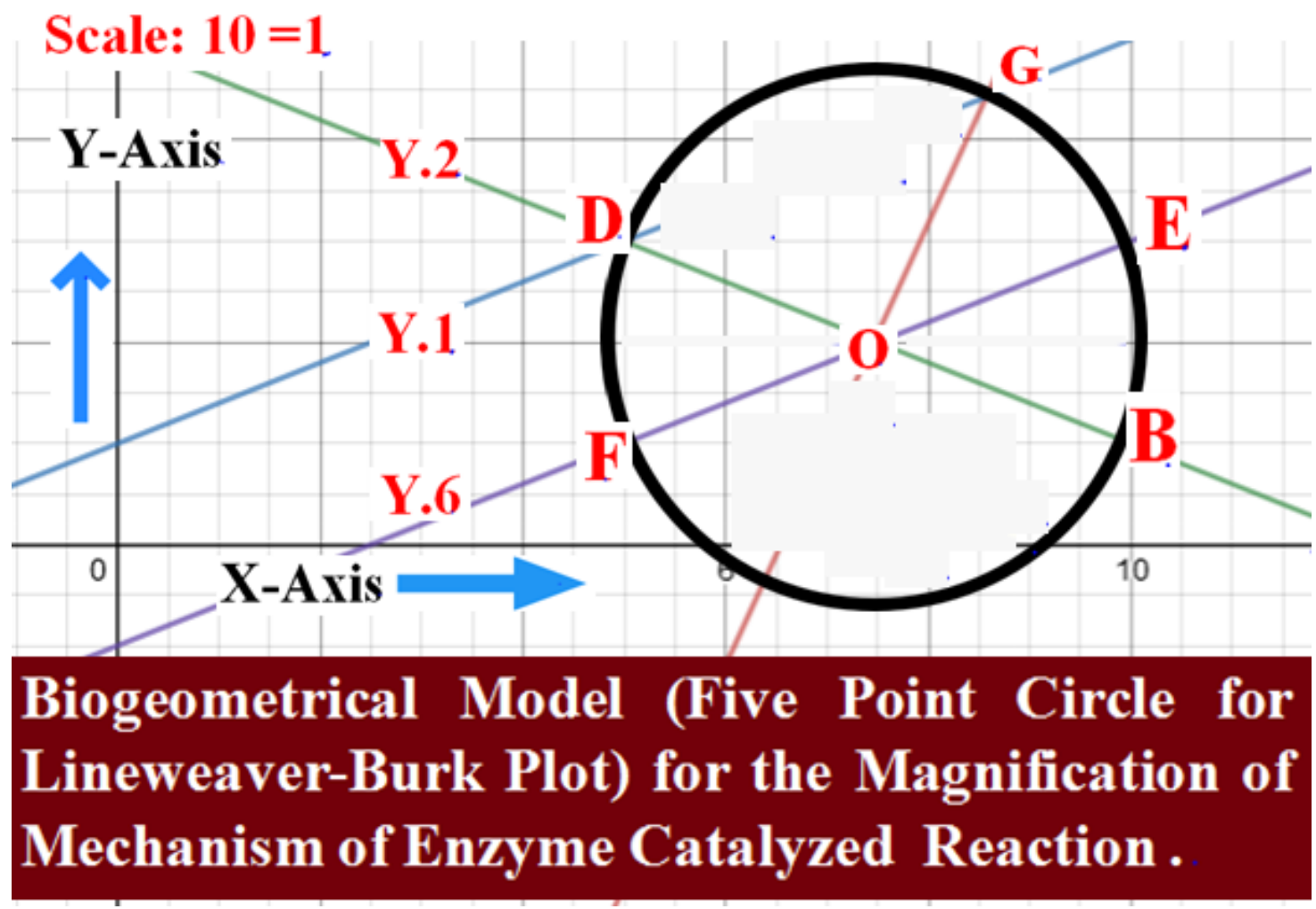

Fig. 8 The bio-geometrical model (five point circle for the triangle (in "double-reciprocal-plot" or

"Lineweaver-Burk-plot" for the kinetic parameters of enzymes) in Enzyme-Biochemistry"

\subsection{The Bio-geometric Model for Enzyme Kinetics}

The figures (Fig. 7 and Fig. 8) resulted in present are dealing with the five points circle for a triangular form of "double-reciprocal-plot" (or "Lineweaver-Burk-plot" for the kinetic parameters of enzymes) in Enzyme-Biochemistry". The five point circle in the attempt is the foundation for the bio-geometrical model for the magnification of the mechanism of enzyme catalyzed reactions. That is to say, the bio-geometrical model is based on the five point circle for the triangle (in "double-reciprocal-plot" or "Lineweaver-Burkplot" for the kinetic parameters of enzymes). The five significant points resulted for the circle with $\mathrm{x}-$ and

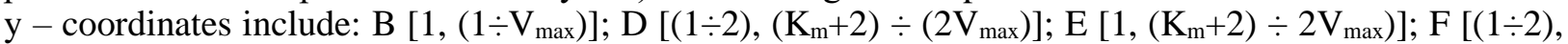
$\left.\left(1 \div \mathrm{V}_{\max }\right)\right]$ and the point " $\mathrm{G}$ ". The $\mathrm{x}$ - coordinate of the point " $\mathrm{G}$ " corresponds to: $\left[\left(\mathrm{V}_{\max }{ }^{2}\right) \div\left(\mathrm{V}_{\max }{ }^{2}+\mathrm{K}_{\mathrm{m}}{ }^{2}\right]\right.$ and the $y$ - coordinate of the point " $G$ " corresponds to: $\left[K_{m}\left(V_{\max ^{2}}{ }^{2} K_{m}\right)+V_{\max }{ }^{2}\right] \div\left[\left(V_{\max }{ }^{2}+K_{m}{ }^{2}\right) V_{\max }\right]$. The $\mathrm{x}$ - coordinate and $\mathrm{y}$-coordinate for the point "O" representing center of circle in the attempt corresponds to: $[(3 \div 4)]$ and $\left[\left(\mathrm{K}_{\mathrm{m}}+4\right) \div\left(4 \mathrm{~V}_{\max }\right)\right]$ respectively.

The bio-geometrical model considers representation of the significant interaction between the enzyme and substrate for the successful release of product through the each and every point on the five point circle 
in the triangle (in "double-reciprocal-plot" or "Lineweaver-Burk-plot" for the kinetic parameters of enzymes). The controlling role of the point, "O", center of circle in each and every event of the biochemical reaction is obligatory (Fig. 9).

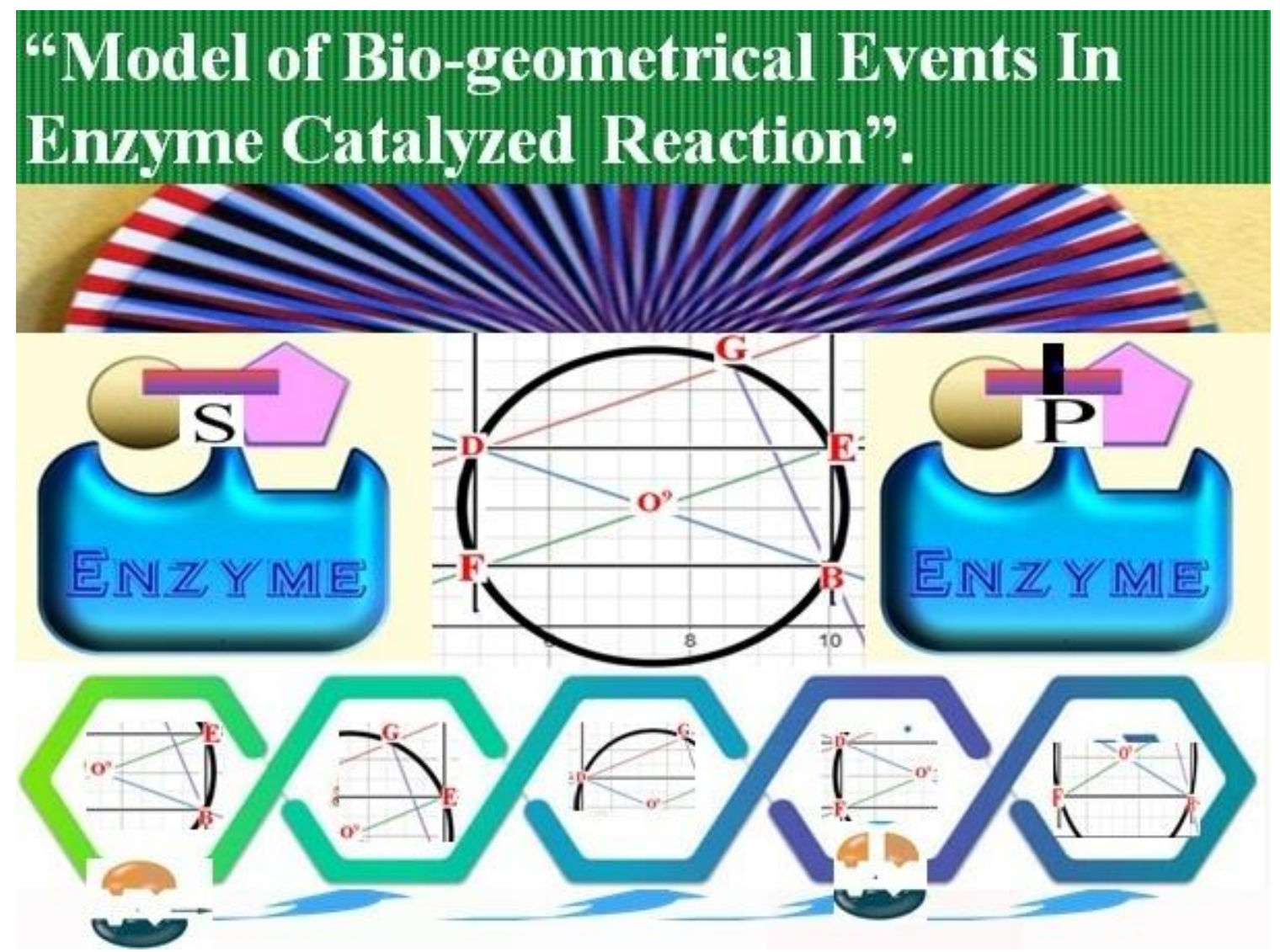

Fig. 9 The bio-geometrical model (five point circle for double-reciprocal-plot / Lineweaver-Burk-plot) for the magnification of mechanism of enzyme catalyzed reaction

The model (Fig. 8) is allotting specific role for the significant events for the biochemical reaction of the enzyme involved catalysis. The events in the "biochemical catalysis" are supposed to be completed through five events, which may be named as, "Bio-geometrical events of enzyme catalyzed reaction". These five events for enzyme catalyzed reaction include: (1) Initial event of interaction of the enzymes and the substrates; (2) The step (or the event) of the first transition state for the formation of enzyme-substrate complex; (3) The event of the second transition state for the formation of enzyme-product complex; (4) The event of release of the product and relieve enzyme and (5) The event of directing the enzyme to continue the reaction. The model utilizes the "triple point serving group on the circle" for the success of each and every event in the biochemical reaction. Thus, there is involvement of the three points including the point "O" for each event in the enzyme catalyzed reaction. The group of points serving for carrying out the event may be classified into five conic sections like: B-O-E; E-O-G; G-O-D; D-O-F and F-O-B.

The correlation between the "five events for enzyme catalyzed reaction" and "triple point event serving groups on the circle" proposed by the bio-geometrical model is explaining the mechanism of enzyme catalyzed reaction as follow:

(a) The "triple point event serving group on the circle" "B-O-E" is concerned with initial event of interaction of enzyme and substrate in the biochemical reaction. Each enzyme is in need of a substrate (specific) to exhibit the best performance in the process of catalysis. In its three dimensional structure, enzyme is with active site for substrate to bind. It is supposed that, the factors of biochemical reaction are responsible for alignment of the enzyme with substrate. The force of attraction between the enzyme and the substrate may be created by the available system for the biochemical reaction for this initial stage. At the initial stage, the catalytic sites of the enzyme are empty. This condition is bringing the substrate and the enzyme close together at faster rate. Therefore, at the low concentration of substrate, there is a steep increase in the rate of reaction.

(b) The "triple point event serving group on the circle" "E-O-G" is supposed to be concerned with the event of the first transition-state for the purpose to form an "enzyme-substrate-complex" in the biochemical reaction. The substrate use to bind to the active site in the structure of enzyme. This 
binding is brought about through hydrogen-bonds (or interaction of hydrophobic nature) (or interactions through the weak Van der Waals forces). Fruitful alignment consequently leads to the formation of the "enzyme-substrate-complex". The event serving group "E-O-G" is helping for the fruitful interaction of the substrate with the active site of the enzyme and formation of "EnzymeSubstrate-Complex" (ESC). There is a need of induction of precise conformational changes in the enzyme to initiate the reaction. This induction is brought about through appropriate (or specific) substrate. That is to say, appropriate (or specific) substrate can induce the precise conformational changes in enzymes needed for catalytic reaction. Soon after binding the substrate to the active site within the structure of the enzyme, there are conformational changes for the rearrangement of critical functional groups. The conformational changes for the rearrangement of critical functional groups ensure the most effective location.

(c) The "triple point event serving group on the circle" "G-O-D" is supposed to be concerned with event of the state of the second transition. The state of the second transition is responsible for the formation of "enzyme-product-complex" (EPC). The event serving group "G-O-D" is supposed to be acting as the key event serving group and convert the "Enzyme-Substrate-Complex" into the "EnzymeProduct-Complex" in the catalysis through the enzyme. As reaction proceeds, the enzyme brings about the essential changes for catalysis. It is supposed that, "triple point event serving group on the circle" "G-O-D" is instantly transforming the enzyme-substrate complex into the enzyme-product complex.

(d) The "triple point event serving group on the circle" "D-O-F" is supposed to be concerned with the event of release of the product and relieve of enzyme from the "Enzyme-Product-Complex". It is supposed that, "triple point event serving group on the circle" "D-O-F" is responsible to make the bond between product and substrate unstable. There may be the force of repulsion between the product and the enzyme, which brings about the release of the product from the "Enzyme-ProductComplex" (EPC) and to proceed to relieve the enzyme.

(e) The "triple point event serving group on the circle" "F-O-B" is supposed to be concerned with the event of directing the enzyme to continue the reaction of catalysis through the available system along with the substrate. The bio-geometrical model is opining role of cofactors or the biochemical agents. The co-factors are essential for conformational changes in the enzymes. The co-factors make the enzymes ready for joining the reaction (catalysis) process. In this regard, the hypothesis of "lock and key" is useful to explain and to understand the mechanisms of actions of the enzymes that have strictspecificity. This hypothesis requires a "rigidity-level", which is incompatible with the current knowledge of structure and confirmation of enzyme molecule (and substrate molecule too). There are agents that cause conformational changes in the enzyme, increasing its efficiency for the catalysis.

The "induced-fit" hypothesis of Koshland is going to serve to explain the last event expected by the bio-geometric model. The "induced - fit" hypothesis introduced the concept of adaptive fitness or induced fitness of enzymes. The adaptive fitness takes into consideration that, the enzyme structure is not rigid, but plastic. This flexible-model allows the enzyme to modify its conformation in the structure when in contact with the new substrate, adapting to it and orienting essential residues to obtain the optimal conformation to continue the reaction. The substrate binds to a small section of the enzyme referred to as the active site. The molecule (or molecules) produced at the end of the reaction is referred to as the product. Once the reaction is complete, the enzyme releases the product and is ready to bind with another substrate. Enzymes are extremely particular, and each enzyme only binds with one particular substrate. So how does the enzyme know whether or not the molecule next to it is the one that it wants? Daniel Koshland offered a solution to this puzzle in 1958 [25]-[27]. The induced-fit model is actually an offshoot of an earlier theory proposed by Emil Fischer in 1894, the lock-and-key model [28]-[31]. The lock-and-key model states that the substrate acts as a 'key' to the 'lock' of the active site. The active site and substrate are exact matches for each other, similar to puzzle pieces fitting together. In this model, only a single substrate is the precise match for the enzyme. Once the enzyme finds its exact counterpart, the chemical reaction can begin [32]. The induced-fit model is generally considered the more correct version. This theory maintains that the active site and the substrate are, initially, not perfect matches for each other. Rather, the substrate induces a change of shape in the enzyme. This is similar to placing your hand in a glove. Getting the first finger in may be difficult, but, once you complete this initial step, the glove slides on easily. 


\subsection{Impact of the "Bio-geometric Model of the Five Points Circle in the Triangular Form of Lineweaver- Burk plot" on the Current Biochemical Assays}

The highest affinity and specificity of enzymes for their substrate determine the demand for and the intensive development of analytical systems based on use of bio-geometrical (statistical tool) methods of the analysis. Therefore, theoretical concepts of the mechanisms of enzyme action, quantitative parameters of reflections of enzyme involved reactions have become extremely important. Many mathematical models describing different bioassay formats have been proposed. However, there is almost no information on the comparative characteristics of these models, their assumptions, and predictive insights. The biogeometrical model is trying its best to suggest a set of criteria for classification of the data on substrate concentration $[\mathrm{S}]$ and velocity (v) of enzyme catalyzed reactions.

The bio-geometrical model seems to be an integral part of the theoretical basis of assay of enzyme activity. The analysis of data on substrate concentration $[\mathrm{S}]$ and velocity (v) of enzyme catalyzed reaction through the proposed bio-geometrical model is going to help to understand the mechanisms of processes that occur in the system. The proposed "Bio-geometrical model" is with a predictive function and allow to evaluate the impact of various factors and parameters on the assay results without long laborious experiments. No doubt, any theoretical model only partially corresponds to a real process. Still, the proposed "Bio-geometrical model" reflects the general principles of the integration of system of functioning of the enzymes according to available system of concentration of the substrate [S]. As a rule, a model of an assay for enzyme kinetics is considered valid if it can be used for the calculation of the Michaelis-Menten constant $\left(K_{\mathrm{m}}\right)$ for given enzyme. In this regard, the proposed "Bio-geometrical model" is going to serve a lot not only for the calculation of the Michaelis-Menten constant $\left(K_{\mathrm{m}}\right)$, but also for determination of the " $Y$ " values corresponding to the "X" values on the five point circle. It may give dimension (dynamic range) of "Y" values for the real form of the well esteemed Lineweaver-Burk plot.

\subsection{Elucidation of the "Five Point Circle" in an easier manner with example for the Analysis of the Data on the Substrate Concentration [S] and velocity (v) of Enzyme Catalyzed Reaction (Experiments/ Attempts that can be Executed / Analyzed with the Current Proposed Plot will be helpful)}

The "bio-geometric model of the five points circle in the triangular form of Lineweaver-Burk plot" exerts applicable influence. It is related to the elucidation of the "Five Point Circle" in an easier manner (with the help of experiment that can be executed / analyzed with the current proposed plot for its reliability. Alternatively, sophisticated numerical and statistical in silico procedures have been developed that provide information not only on the parameterization but also on the reliability of the estimated parameters and whether the applied mechanistic model can be used for the description of the obtained experimental data in the first place (model discrimination). Such an approach is generally referred to as model-based experimental analysis.

Principally, there are three distinct components considered in the attempt to a "Bio-geometric Model of the Five Points Circle in the Triangular Form of Lineweaver-Burk plot" - based analysis: (a) the experimental data; (b) a model describing the experiment from which the experimental data was obtained; and (c) fitting of the data by minimizing a function that reflects the deviation between model prediction and experimental data. The data considered (Table 1, the first three columns) in the present attempt belongs to: Analytical Chemistry (chapter 13/ page 902) [33] (the oxidation of catechol (the substrate) to $o$-quinone by the enzyme $o$-diphenyl oxidase). Catechol oxidase is a copper-oxidase that contains a type 3 di-copper co-factor. This enzyme serve to catalyze "Ortho-di-phenol-oxidation" into ortho-quinone coupled with the oxygen-reduction to water. It is present in a variety of species of plants and fungi including Ipomoea batatas (L) and Camellia sinensis (L).

Table 1 Data on concentration of the substrate (catechol) [S] and the rate reaction (v) catalyzed by enzyme- diphenyl-oxidase [33]

\begin{tabular}{|c|c|c|c|c|c|c|c|}
\hline S/No & [S] & $\overline{\mathrm{V}}$ & $\left(\mathrm{V}_{\max }-\mathrm{v}\right)$ & {$\left[\mathrm{S}\left(\mathrm{V}_{\max }-\mathrm{v}\right)\right]$} & {$\left[(4-\mathrm{S}) \div 4 \mathrm{~V}_{\max }\right]=\mathrm{A}$} & $\overline{[S \div 4 \mathrm{~V}]=\mathrm{B}}$ & Quotient $(\mathrm{A}+\mathrm{B})$ \\
\hline 1 & 1 & 2.7874 & 5.2126 & $5.2126^{*}$ & 0.09375 & 0.08968 & $0.18343^{* * * *}$ \\
\hline 2 & 2 & 4.1343 & 3.8657 & $7.7314^{*}$ & 0.0625 & 0.12093 & $0.18343^{* * *}$ \\
\hline 3 & 4 & 5.4514 & 2.5486 & $10.1944^{*}$ & 0.0000 & 0.18343 & $0.18343^{* * *}$ \\
\hline 4 & 5 & 6.8011 & 1.1989 & 5.9945 & 0.03125 & 0.18379 & 0.21504 \\
\hline 5 & 8 & 8.0000 & 0.0000 & 0.000 & -0.1250 & 0.2500 & 0.1250 \\
\hline 6 & 10 & 8.0000 & 0.0000 & 0.0000 & -0.1875 & 0.3125 & 0.1250 \\
\hline
\end{tabular}

Note: The figures in the column of $[\mathrm{S}]$ and $(\mathrm{V})$ are from readymade data from source reference. The figures in other remaining columns are calculated figures for obtaining the "Quotient" for the present attempt on Bio-geometric Model of the Five Points Circle in the Triangular Form of Lineweaver-Burk plot. *: The data on $[S]$ and $(V)$ exhibiting increasing order in its $\left[S\left(V_{\max }-v\right)\right]$ and constancy in the final Quotient $(* * *)$ are recommended for further processing for the Five Points Circle in the Triangular Form of Lineweaver-Burk plot. 


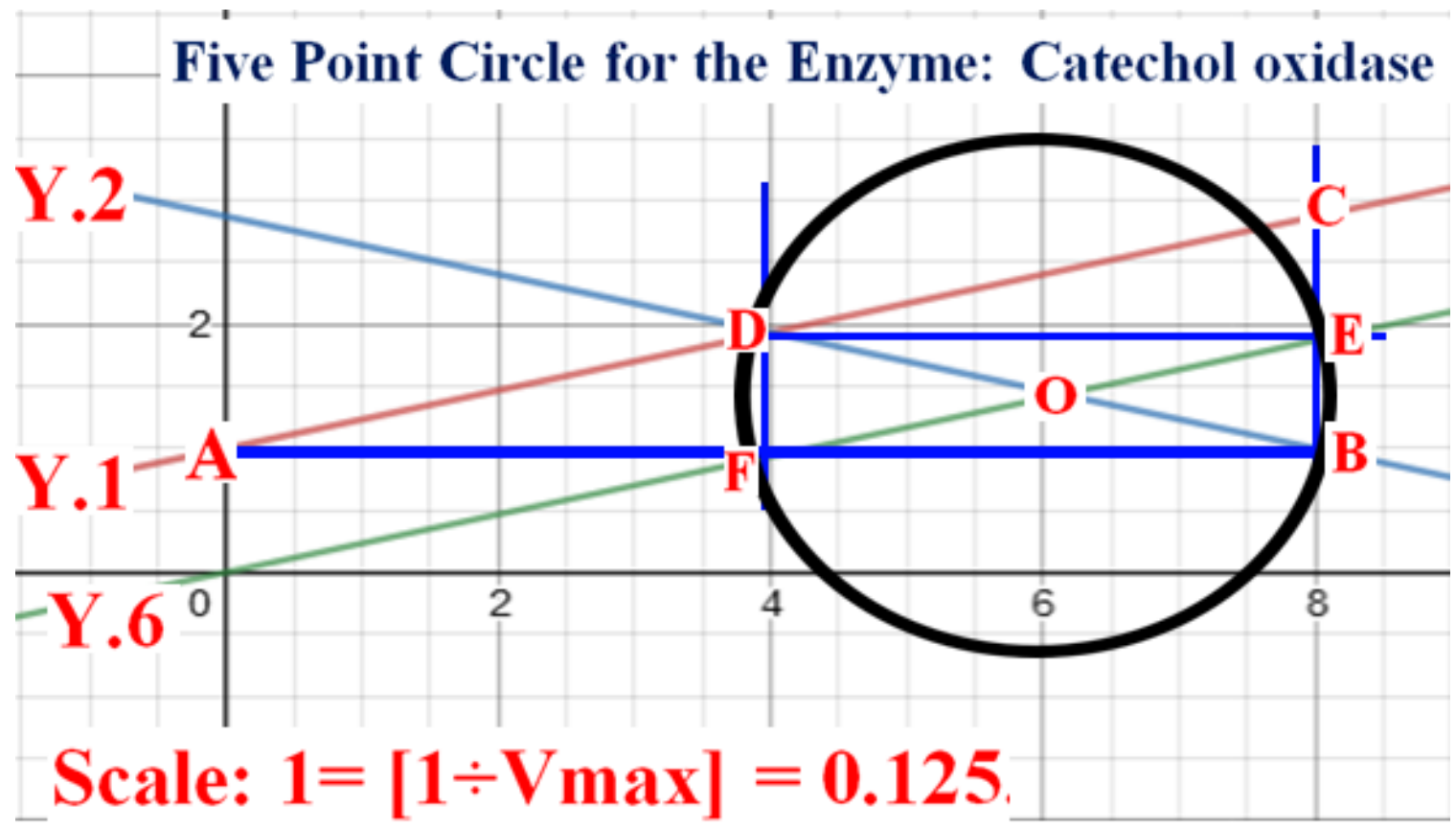

Fig. 10 Elucidation of the "Five Point Circle" in an easier manner with example for the analysis of the data on the substrate concentration [S] (catechol) and velocity (v) of enzyme (catechol oxidase) catalyzed reaction (Experiments/ Attempts that can be executed / analyzed with the current proposed plot will be helpful)

Table 1 and Fig. 10 are dealing with processing the data on concentration of the substrate (catechol) [S] and the rate reaction (v) catalyzed by enzyme-diphenyl-oxidase for elucidation of the "five point circle" in an easier manner that can be executed / analyzed with the current proposed plot will be helpful. The figures in the column of $[\mathrm{S}]$ and $(\mathrm{V})$ are from readymade data from source reference. The very first attempt is screening the data for eligibility of principles considered for the "Bio-geometric model of the five points circle in the triangular form of Lineweaver-Burk plot". The increasing order in the parameters: $\left(\mathrm{V}_{\max }-\mathrm{v}\right)$ and $\left[\mathrm{S}\left(\mathrm{V}_{\max }-\mathrm{v}\right)\right]$ (column: 4 and 5 in Table 1$)$ is the very first criteria for the eligibility of data on concentration of the substrate $[\mathrm{S}]$ and the rate reaction (v) catalyzed by enzyme. The occurrence of constancy in "Quotient" (The eighth column in table-1) is the second criteria for the eligibility of data on concentration of the substrate [S] and the rate reaction (v) catalyzed by enzyme. The "Quotient" considered in the attempt is calculated through addition of parameters: " $A$ " and " $\mathrm{B}$ " (The sixth and seventh column in Table 1). The mathematical equations for the line Y.1; line Y.2 and line Y.6 in Fig. 10 are as follow:

$\mathrm{Y} .1=0.23375 \mathrm{x}+1$.

$\mathrm{Y} .2=-0.23375 \mathrm{x}+2.87$.

$\mathrm{Y} .6=0.23375 \mathrm{x}+0.001015625$.

The scale for plotting line Y.1; line Y.2 and line Y.6 on computerized graph corresponds to: the graph: $1=0.125$. The intersection of line Y.2 and line Y.6 is giving the $x$-co-ordinate for the center for the five point circle in the attempt.

Y.6 $=$ Y.2.

$0.23375 \mathrm{x}+0.001015625=-0.23375 \mathrm{x}+2.87$.

$0.46750 \mathrm{x}=2.87-0.001015625=2.868984375$.

$x=6.1368$.

The $x$-coordinate for the center for the five-point circle in the attempt is 6.1368 , which correspond to 0.7671 in the graph (scale for graph is $1=0.125$ ). The $y$-co-ordinate for the center for the five point circle in the attempt can be obtained through keeping the $x$-value $(x=6.1368)$ in either equation for the line Y.2 or line Y.6. Accordingly, the $y$-co-ordinate for the center for the five point circle in the attempt is equal to: $1.46744(0.23375 \times 6.1368+0.001015625=1.46447)$. According to the scale considered for computerized graph (Fig. 10) is $1=0.125$. Therefore, the $y$-co-ordinate for the center for the five point circle in the attempt is: 018343. 
The present attempt is suggesting to consider the screening the data for eligibility and then calculation of "Quotient" for each pair of $[\mathrm{S}]$ and $(\mathrm{V})$ in the data. The quotient is the $y$-co-ordinate for the center for the five point circle, the $x$ - coordinate for which correspond to: $(3 \div 4)$.

\subsection{Significance of the "Bio-geometric Model for Enzyme Kinetics"}

The bio-geometric model for enzyme kinetics is demonstrating five steps for the completion of enzyme catalyzed biochemical reaction. The model opined the two transition steps in the mechanism of enzyme catalyzed reactions. These two transition steps may be correlated with abrupt transitions between apparently linear sections. In some enzymes, these transitions correspond to abrupt increases in the apparent Micgaelis-Menten constant $\left(K_{\mathrm{m}}\right)$ and maximum velocity $\left(V_{\max }\right)$.

The generalized reciprocal initial-rate equation (Lineweaver-Burk plot) for a multisite enzyme requires several restrictions to be put on it in order to generate such plots. Through the concept of five point circle, the mathematical conditions may be explored for the ease in order to generate the generalized reciprocal initial-rate equation (Lineweaver-Burk plot) for a multisite enzyme.

The bio-geometric model for enzyme kinetics demonstrate minimal requirement for generation of two transitions in the reaction. The minimal requirement may correspond to the physical factors like negative co-operability of the enzyme followed by positive co-operability of the enzyme. Further, this system may be affecting the catalytic rate constant for the reaction.

The line segment parallel to $\mathrm{x}$ - axis, passing from the center of five point-circle in bio-geometric model for enzyme kinetics with the dimension of $1 \div 4$ is analogous to the apothem for the regular octagon inscribed within the circle. The dimension of this apothem for each and every enzyme is constant.

The bio-geometric model for enzyme kinetics tried to establish fortified bio-geometrical background for the enzyme kinetics, which may open a new avenue in enzymology.

\section{Conclusion}

The significant and concyclic points resulted for the five points circle for triangular form of LineweaverBurk plot with $\mathrm{x}-$ and $\mathrm{y}$ - coordinates include: $\mathrm{B}\left[1,\left(1 \div \mathrm{V}_{\max }\right)\right]$; D $\left[(1 \div 2),\left(\mathrm{K}_{\mathrm{m}}+2\right) \div\left(2 \mathrm{~V}_{\max }\right)\right]$; $\left.\mathrm{E}\left[1,\left(\mathrm{~K}_{\mathrm{m}}+2\right) \div 2 \mathrm{~V}_{\max }\right)\right] ; \mathrm{F}\left[(1 \div 2),\left(1 \div \mathrm{V}_{\max }\right)\right]$ and the point "G". The $\mathrm{x}$ - coordinate of the point "G" corresponds to: $\left[\left(\mathrm{V}_{\max }{ }^{2}\right) \div\left(\mathrm{V}_{\max }{ }^{2}+\mathrm{K}_{\mathrm{m}}{ }^{2}\right]\right.$ and the $\mathrm{y}$ - coordinate of the point " $\mathrm{G}$ " corresponds to: $\left[\mathrm{K}_{\mathrm{m}}\right.$ $\left.\left(\mathrm{V}_{\max }{ }^{2}+\mathrm{K}_{\mathrm{m}}\right)+\mathrm{V}_{\max }{ }^{2}\right] \div\left[\left(\mathrm{V}_{\max }{ }^{2}+\mathrm{K}_{\mathrm{m}}{ }^{2}\right) \mathrm{V}_{\max }\right]$. The $\mathrm{x}$ - coordinate and $\mathrm{y}$ - coordinate for the point "O" representing center of circle in the attempt corresponds to: $[(3 \div 4)]$ and $\left[\left(\mathrm{K}_{\mathrm{m}}+4\right) \div\left(4 \mathrm{~V}_{\max }\right)\right]$ respectively. The bio-geometrical model considers representation of the significant interaction between the enzyme and substrate for the successful release of product through the each and every point on the five point circle in the triangular form of Lineweaver-Burk plot for enzyme kinetics. The controlling role of the point, "O", center of circle in each and every event of the biochemical reaction is obligatory. The bio-geometrical model is hypothesing the completion of enzyme catalyzed reaction through five events correlating with the five "triple point event serving groups" on the five point circle for triangular form of Lineweaver-Burk plot. This model is based on the five point circle in the triangular form of Lineweaver-Burk plot for enzyme kinetics. There is involvement of the three points including the point "O" for each event in the enzyme catalyzed reaction. The groups of points serving for carrying out the event are classified into five conic sections like: B-O-E; E-O-G; G-O-D; D-O-F and F-O-B. The bio-geometrical model is correlation between the "five events for enzyme catalyzed reaction" and "triple point event serving groups on the circle" in triangular form of Lineweaver-Burk plot for understanding the mechanism of enzyme catalyzed reaction.

\section{Conflict of Interests}

The authors declare that there is no conflict of interests regarding the publication of this paper.

\section{Acknowledgements}

Academic support and inspiration received from Agricultural Development Trust, Baramati exert a grand salutary influence. Authors received expertise support from M. S. Okundamiya. 


\section{References}

[1] A. S. Ozdemir, S. Goktepe, and I. Kepceoglu, "Using mathematics history to strengthen geometric proof skills," Procedia - Soc. Behav. Sci., vol. 46, pp. 1177-1181, 2012.

[2] N. Altshiller-Court, College geometry: An introduction to the modern geometry of the triangle and the circle, $2^{\text {nd }}$ ed. (revised), Mineola, New York: Dover Publications, Inc. 2007.

[3] B. Savizi, "Applicable problems in the history of mathematics: practical examples for the classroom," Teach. Math. Appl., vol. 26, no. 1, pp. 45-50, Mar. 2007.

[4] H. F. Baker, Principles of geometry, volume 2, Cambridge: Cambridge University Press, 1922.

[5] C. B. Boyer, A history of mathematics, New York: John Wiley \& Sons, 1968.

[6] C. J. Bradley, The algebra of geometry: Cartesian, areal and projective co-ordinates, UK: Bath, Highperception Ltd., 2007.

[7] C. Tzanakis, A. Arcavi, C. C. de Sa, M. Isoda, C. Lit, M. Niss, J. P. de Carvalho, M. Rodriguez, and M.-K. Siu, "Integrating history of mathematics in the classroom: an analytic survey," Hist. Math. Educ. ICMI Study, pp. 201240, 2000.

[8] J. Casey, "Nine-point circle theorem," in A Sequel to the First Six Books of Euclid (4th ed.), London: Longmans, Green, \& Co, 1886.

[9] H. S. M. Coxeter, and S. L. Greitzer, Geometry Revisited, Washington, DC: The Mathematical Association of America, 1967.

[10] D. Fraivert, "New applications of method of complex numbers in the geometry of cyclic quidrilaterals," Int. J. Geometry, vol. 7, no. 1, pp. 4 - 16, 2018.

[11] M. D. de Villiers, "The nine-point ellipse: a rediscovery and proof by computer," Int. J. Mathematical Educ. Sci. Technol., vol. 37, no. 1, pp. 7 - 14, 2006.

[12] D. Andrica and D. S. Marinescu, "New interpolation inequalities to Euler's R $\geq 2$ r," Forum Geometricorum, vol. 17, pp. 149-156, 2017.

[13] G. A. Venema, Exploring Advanced Euclidean Geometry with GeoGebra, USA: Mathematical Association of America, Inc, 2013.

[14] B. M. Ratcliffe, "Towards a better understanding of Olinde Rodriguez and his circle: family and faith in his life and career", Chapter 3, in S. Altmann, E. L. Ortiz, (eds.), Mathematics and Social Utopias in France: Olinde Rodrigues and His Times, History of Mathematics, 28, American Mathematical Society, pp. 39-70, 2006.

[15] J. Kocik, and A. Solecki, "Disentangling a triangle," Amer. Math. Monthly, vol. 116, no. 3, pp. 228-237, 2018.

[16] R. A. Johnson, Modern geometry: An elementary treatise on the geometry of the triangle and the circle, Boston, MA: Houghton Mifflin, 1929.

[17] E. A. Hubin, A. Fay, C. Xu, J. M. Bean, R. M. Saecker, M. S. Glickman, S. A. Darst, and E. A Campbell, "Structure and function of the mycobacterial transcription initiation complex with the essential regulator RbpA," Biochemistry and Chemical Biology Structural Biology and Molecular Biophysics, eLife 2017; 6:e22520, doi: 10.7554/eLife.22520

[18] D. Wells, The penguin dictionary of curious and interesting Geometry, London: Penguin, p. 150, 1991.

[19] V. B. Khyade, A. Hershko, and S. K. Dongare, "Euler's line for enzyme kinetics," Int. J. Recent Acad. Res., vol. 1, no. 9, pp. 532-542, 2019.

[20] D. W. Mitchell, “A heron-type formula for the reciprocal area of a triangle," The Mathematical Gazette, vol. 89, 494, 2005.

[21] M. de Villiers, “A generalization of the nine-point circle and Euler line," Pythagoras, vol. 62, pp. 31 - 35, 2005.

[22] A. Bell, "Hansen's right triangle theorem, its converse and a generalization," Forum Geometricorum, vol. 6, pp. 335342,2006

[23] U. T. Jankvist, "A categorization of the 'whys' and 'hows' of using history in mathematics education," Educ. Stud. Math., vol. 71, no. 3, pp. 235-261, 2009.

[24] A. Posamentier, Advanced Euclidean geometry, Emeryville: Key College Publishing, 2002.

[25] "Chymosin - GMO Database". GMO Compass. European Union. 10 July 2010. Archived from the original on 26 March 2015. Retrieved 1 March 2015.

[26] P. Molimard, and H. E. Spinnler, "Review: Compounds Involved in the Flavor of Surface Mold-Ripened Cheeses: Origins and Properties". Journal of Dairy Science, vol. 79, no. 2, pp. 169-184, 1996.

[27] H. Guzmán-Maldonado, and O. Paredes-López, "Amylolytic enzymes and products derived from starch: a review", Critical Reviews in Food Science and Nutrition, vol. 35, no. 5, pp. 373-403, 1995

[28] I. Alkorta, C. Garbisu, M. J. Llama, J. L. Serra, "Industrial applications of pectic enzymes: a review", Process Biochemistry, vol. 33, no. 1, pp. 21-28, 1998.

[29] P. Bajpai, "Application of enzymes in the pulp and paper industry", Biotechnology Progress, vol. 15, no. 2, pp. 147$157,1999$.

[30] C, G. Begley, S. Paragina, and A. Sporn, "An analysis of contact lens enzyme cleaners", Journal of the American Optometric Association, vol. 61, no. 3, pp. 190-194, 1990.

[31] P. L. Farris, "Economic Growth and Organization of the U.S. Starch Industry", In J. N. BeMiller, R. L. Whistler (eds.), Starch Chemistry and Technology (3rd ed.), London: Academic, 2009.

[32] D. A. Holman, G. D. Christian, J. Ruzicka, "Titration without Mixing or Dilution: Sequential Injection of Chemical Sensing Membranes," J. Anal. Chem., vol. 69, no. 9, pp. 1763-1765, 1997.

[33] D. A. Holman, G. D. Christian, J. Ruzicka, "Kinetic methods", in Analytical Chemistry, chapter 13, vol. 2, pp. 881939, 1997. http://dpuadweb.depauw.edu/harvey_web/eTextProject/pdfFiles/Chapter13.pdf 